\title{
دور مناهج التربية الفنية في تنمية قيم المواطنة لدي الطفولة المتأخرة"
}

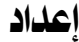

د/حامد سالم جمعه عزب

أستاذ مشارك بجامعة الطائف - المملكة العربية السعودية

د/عبد العزيز عبد الرحمـــالدقيلـــ

أستاذ مساعد بجامعة الطائف - المملكة العربية السعودية

م / إبراهيم سلامة لافحسـ اليمانحسـ الثراريـ

أستاذ مساعد بجامعة الطائف - المملكة العربية السعودية
د/بمدي حسين السيد النحيف

أستاذ بكلية الفنون التطبيقية - جامعة حلوان- مصر

ه / إيناس أحمد عزت حماد

أستاذ مشارك بجامعة الطائف - المملكة العربية السعودية

د /فيصلر عبد الوهاب بخيت الزهـرانحسـ

أستاذ مساعد بجامعة الطائف - المملكة العربية السعودية

\section{مجلة بحوث التربية النوعية ـ جامعة المنصورة}

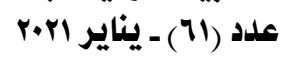

تم تمويل هذا البحث برعاية عمادة البحث العلمي ، جامعة الطائف ، المملكة العربية السعودية ( رقم المشروع البحثي

$$
(1-\varepsilon \varepsilon .-710 \text {. }
$$




\title{
دور هناهج التربية الفنية في تنمية قيم المواطنة لدي الطفولة المتأخرة
}

\author{
إعداد \\ دمجديس.ر.

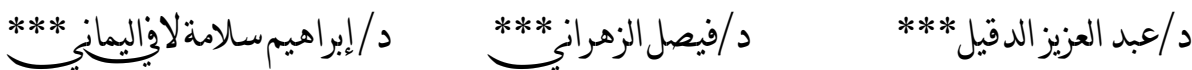

unil|

تعد دراسة الطفولة جزءا هاما من الاهتمام بالحاضر والمستقبل معا حيث يشكل الأطفال

شريحة واسعة من المجتمـع ـ فهى واحدة من الدراسات التى يستدل منها على تبللور الوعى العلمى درى

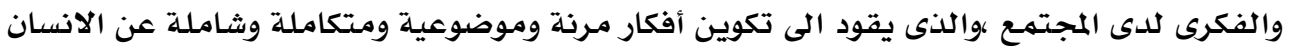
وحاضـره ومستقبـله .

ونظرا للتغير والتطور السريع الذي شمل جميع نواحي الحياة الإجتماعية والاجتماعية

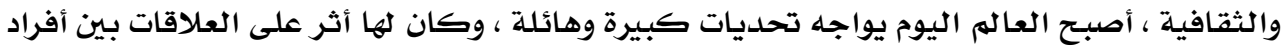

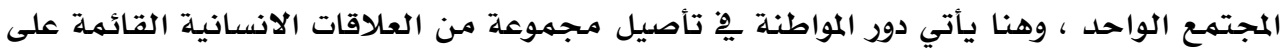

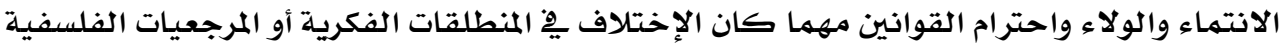

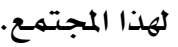
ولقد تعالت الاصوات المنادية بضرورة تعليه وتعلهم المواطنة من خلال المناهج الدراسية وهي

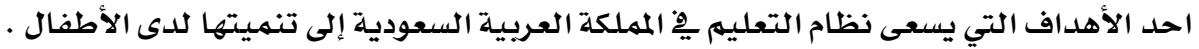
وهدف البحث إلى التعرف على قيم المواطنة التي تسعى مناهج التربية الفنية إلى تنميتها

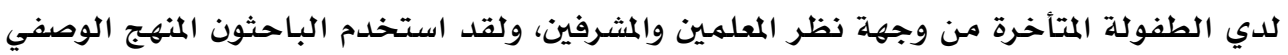

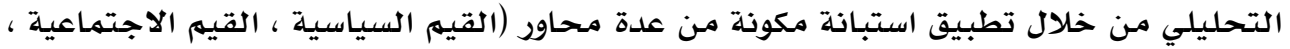

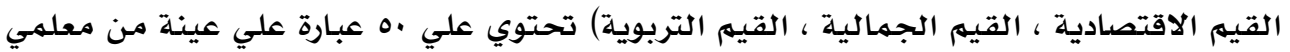

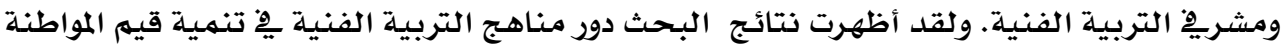

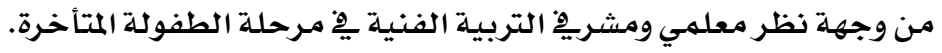
ولقد توصل الباحثون الى مجموعة من النتائج والتوصيات ، والتي يمكن الاستفادة منها من

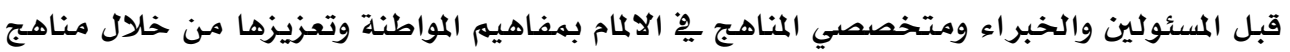
التربية الفنية.

" أستاذ بكليـة الفنون التطبيقية - جامعة حلوان- مصر

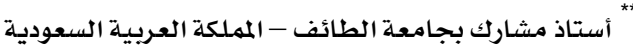
أستاذ مساعد بجامعة الطائف - المملكة العربية السعودية 
مع بـاية القرن العشرين حدث العديد من التطورات والأوضاع التي جعلت موضوع المواطنة

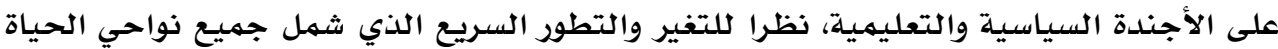

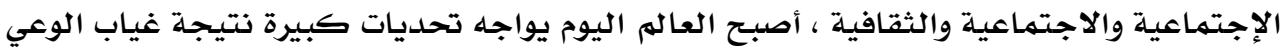

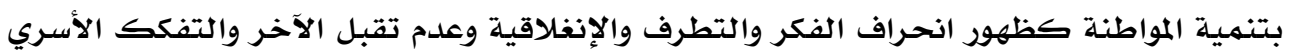

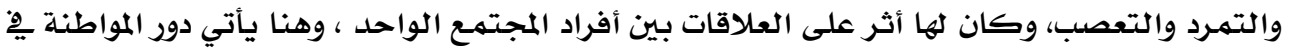

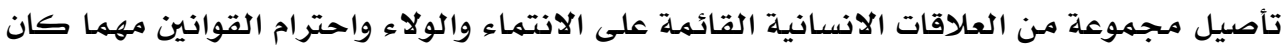

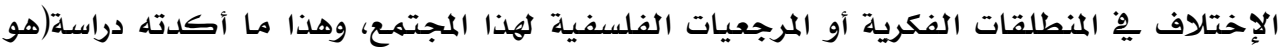

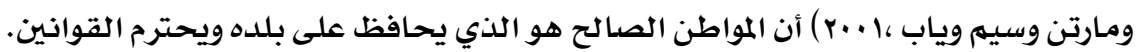

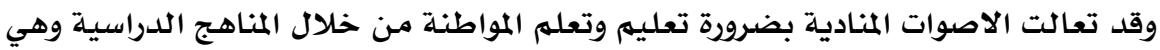

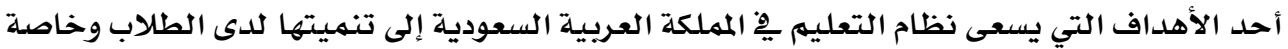

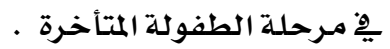
وقد اهتمت المملكة العربية السعودية بالمناهج وتطويرها بصفة عامـة ومناهج التربية الفنيـة

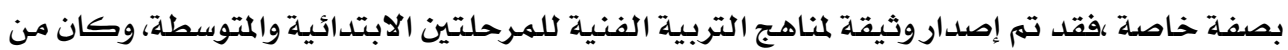

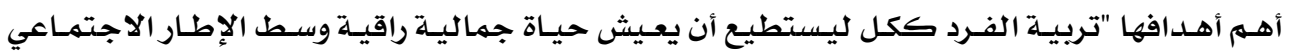

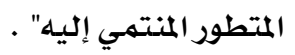

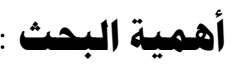

ا ـ الكشف عن دور مناهج التربية الفنية يِّ تنمية قيم المواطنة لدى الطفولة المتأخرة ،على اعتبار

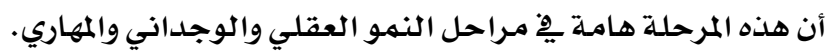

r. يزداد الاهتمام بموضوع المواطنة يِّ ظل العولمة حيث يتضمن مفاهيم انسانية حديثة تتاثر

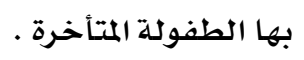

ץ. الاستفادة من نتائج هذه الدراسة للمسئولين والخبر اء ومتخصصي المناهج يِّ الاملمام بهفاهيم

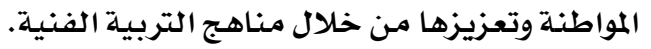

هدف البحث

$$
\text { ويهدف البحث إلى تحقيق ما يلي: }
$$

ا. التعرف على قيم المواطنة التي تسعى مناهج التربية الفنية إلى تنميتها لدي الطفولة المتأخرة.

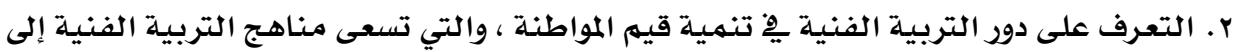

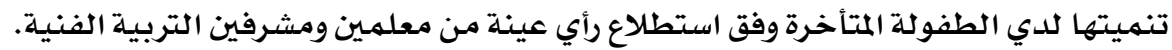


وقد تحددت يِّ التساؤلات التالية:

1- ماهي قيم المواطنة التى تسعى مناهج التربية الفنية إلى تنميتها لدى الطفولة المتأخرة ؟

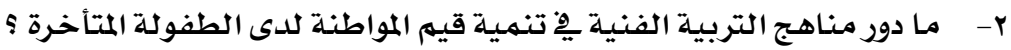

هنهم البمث:

اتبعت الدراسة المنهج الوصفي التحليلي.

\section{همددات الدراسة:}

اقتصرت هذه الدراسلة علي معلمي ومشرفى التربية الفنية لمرحلة الطفولة المتأخرة. - اقتصرت الدراسة على القيم السياسية والاجتماعية والاقتصادية والجمالية والتربوية فقط.

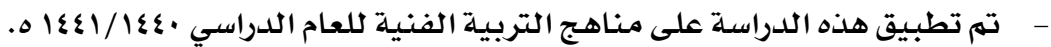

\section{هصطاتحات الدراسة:}

استخدم ِِّْ هذا البحث المصطلحات الآتية:

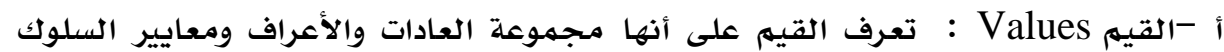

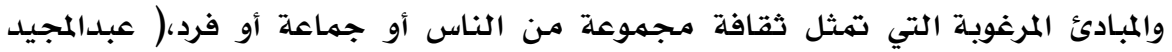

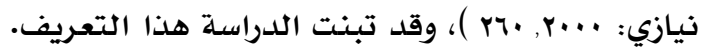

ب -المواطنة: لقد أجمح الكثير ممن تناولوا مفهوم المواطنة على الربط بين مفهومي الحقوق

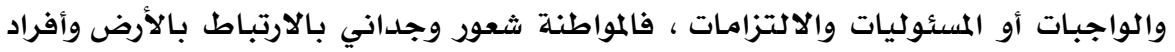

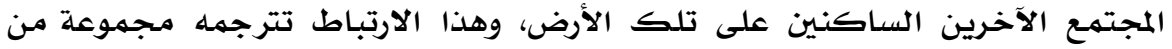

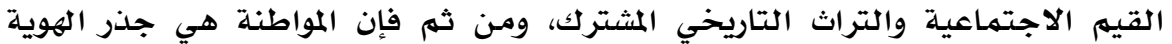
الاجتماعية وعصب الكينونة الاجتماعية. وهناك من عرفها على أنها صفة المواطن الذي يتمتع بالحقوق ويلتزم بالواجبات التي

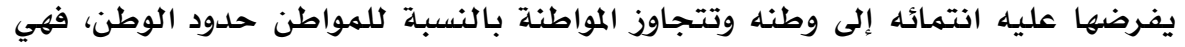

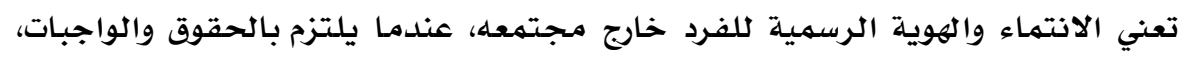

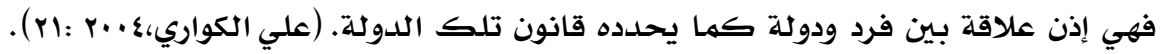

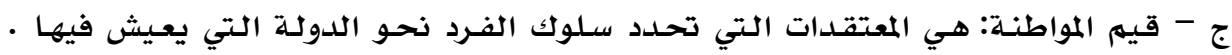

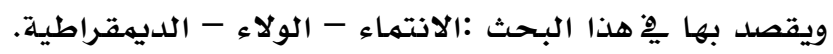

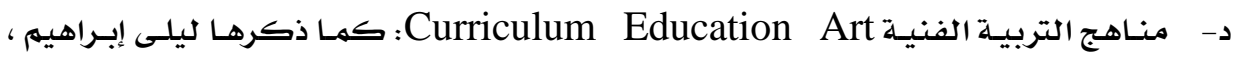

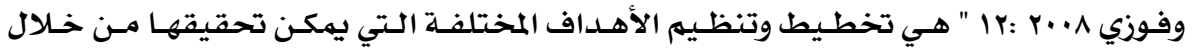

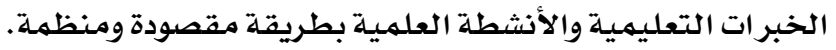


ظهرت العديد من الأدبيات التي تنادي بضرورة التربية من أجل المواطنة ، والتي تؤكد على أنه يجب أن يتجه التعليه بشكل أساسي نحو غرس قيم المواطنة لسليمة (Harland,2000,26) فالتربية بهدف المواطنة : هي غرس المعرفة والاتجاهات والقيم والمبادئ المرغوب فيها لدى الطلاب لإعدادهم ،ليكونوا قادرين على تحمل المسئولية ولديهم القدرة على المشاركة يِّ تقديم الحلول

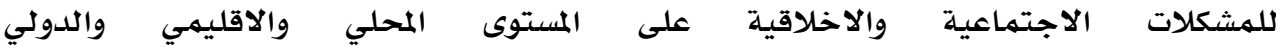
.(Bugliarello,G,2002,64)

لذا يتطلب الأمر ِِّ ضوء هذه التحديات والمشكلات ،بناء منظومـة من القيم والمبادئ

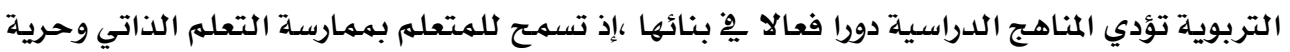
الفكر والأمل واقتراح الحلول للمشكلات ، كما تعمل على تقديم الخبر ات التي تسهمح بالنمو المتكامل للفرد وتتيح له اكتشاف مهارته وقدراته وإمكانياته ، وتؤدي إلى بناء الوعي واحترام الاختلافات ِيْ الرؤي والتفكير ، وتحقيق الفهم المتبادل ويمثل ذلك مكونات هامة لقيم المواطنة (جون دانييل: ا. بr.

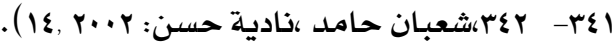
وتعد التربية الفنية إحدى المواد الدراسية التي تعمل على توجيه سلوك الطالب بشكل إيجابي ،حيث لا تهدف التربية الفنية فقط إلى تعلهم مهارات الرسهم أو النحت أو التلوين ، إنما هي المحرك الأساسي لقدرات الطالب الإبداعية، من خلال تنظيم أفكاره وترتيبها وتنسيقها تساعد على ابتكار إبداعات ترفع من حسـه العام ، بحيث يتم تعديل سلوكه إيجابيا نحو نفسـه وبيئته من خلال النظرة الإبداعية الفنية التي يكتسبها (Daignault,2003;Michalko,2002,18-22) وتجعل تفكيره غير تقليدي ولديه تذوق وحس فني يميل إلى حب الجمال والطبيعة ومكوناتها الأمر الذي ينعكس على سلوكه بشكل إيجابي. من هنا تعد المواطنة مطلب تريوي ، فالتربية تهدف عامـة إلى الزيادة والنمو والتحسين والإصلاح والتطوير والتثقيف المستمر، وتنمية القدرات العقلية الفطرية والمكتسبة وبناء الجوانب الخلقية والنفسية السوية وتمثل تلك العناصر التربوية للمواطنة (ناصيف نصار:Y،ه...r)، ولتحقيق ذلك يؤكد التربويين على ضرورة تطوير المناهج الدراسية بحيث تتمحور حول المتعلهم التي تركز على اهتمامـاته وميوله ورغباته وحاجاته(Ross,2002,27) وعلى المشاركة الفعالة يِّ عملية التعلهم ، وبالتالي يصبح من الضروري أن يجسد المنهج مفاهيم وقيه المواطنة ومهاراتها، من خلال

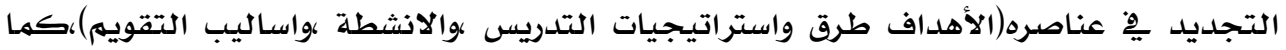
يؤكد (Smith,2003,15) انه يجب أن تحتوي المناهج الدراسية على العديد من المفاهيم والقضايا 
مجلة بحوث التربية النوعية-علدد

والمثكلات المجتمعية والقيم المرتبطة بالمواطنة كالتنوع والتعددية والمساواة والعدالة والمسئولية المجتمعية، بالإضافة إلى توافر العديد من المهارات المرتبطة لممارسـة المواطنة كالتفاعل والاتصال

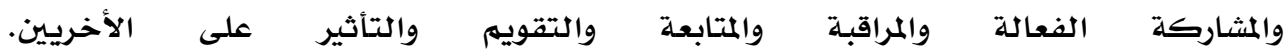
.(,2004,187 Patrick,2003,163;Barnes)

ويضيف (Georon,2003,187) أن اكتساب قيهم المواطنة يتتم من خلال ممارسة الأنشطة

التربوية التي يتم فيها : التقبل وقبول الآخر، والاستيعاب والفهم ،ومعرفة القيه وأهميتها ، والتوقع الإيجابي بأهمية المثاركة ، وتحمل المسئولية،والتمسك بالقيه المدنية ،باعتبارها آلية لتشكيل مناخ

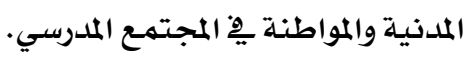

ومن هنا يتجلى الدور الحيوي للمؤسسات التعليمية ِِّ توعية الطلاب بأهمية الحفاظ على الوطن ومكتسباته السياسية والاجتماعية والاقتصادية، ومن أهم قطاعات تلك المؤسسات التعليمية

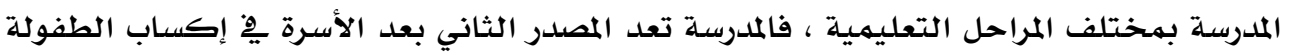
التوجيهات الوطنية وخاصـة أن مرحلة المدرسة تتزامن مـع مرحلة تبللور القناعات الوطنية وتشكيلها

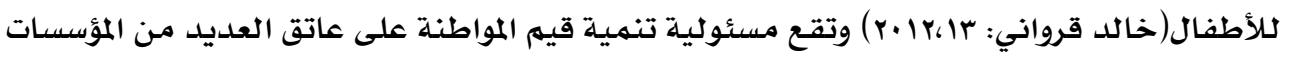
الحكومية وغير الحكومية ، لكن المسئولية الأساسية تقع على التي تحمل رؤية فلسفية محددية وواضحة المعالم (Cogan\&Detticott,2000,132) فالمدرسة بوصفها مؤسسة تربوية هي البوتئة البوتقة

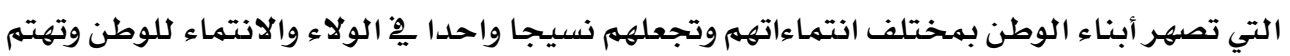
بتحويل قيهم المواطنة إلى أهداف وسلوكيات مكتسبة من قبل الطلاب فالانتماء للوطن يعد من أهم القيم التي يتحتهم على المدرسة أن تشدد على تنميتها لدى الطلاب ،نظرا لما يترتب عليها من

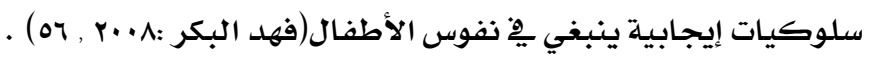
كما أن المدرسة تعد وسيلة مهمة من وسائل تعميق قيم المواطنة بجميع أبعادها، ليس فقط الاتجاهات والقناعات الوطنية الإيجابية لدي الأطفال ، بل يتعدى دورها ذلك إلي تثقيف الطلاب

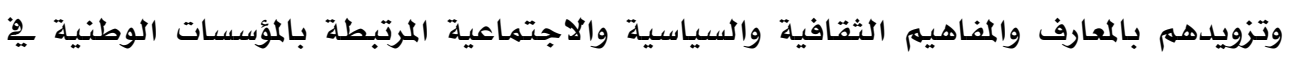
المجتمـع.

وتسعى التربية الفنية مـع باقي المواد الأخرى إلى تحقيق أهداف المجتمع من خلال المدرسسة عن طريق إعداد جيل واعد مدرك ما عليه من حقوق وواجبات، والرقي بذاته ، وقادر على حل مشكلاته ،وحل مشكلات المجتهـع الذي ينتمي إليه.

وتنبثق أهمية التربية الفنية من أهمية الأهداف التي تسعى إلى تحقيقها ، فمنهج التربية

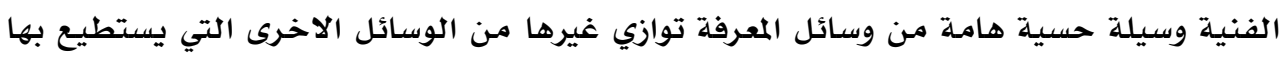


الطفل أن يصل إلى فهم بيئته ، فمن خلال استخدام الرسوم والصور المتنوعة والمنتجات الفنية والتي تحمل ِِِ طياتها العديد من المفاهيه والأفكار البناءة ، يمكن أن يتعلهم الطفل الدقة والعناية والترتيب والتنسيق ، وكذلك طرق التفكير المختلفة وأساليب تطبيقها ِِّ المجالات المختلفة إذ يستطيع الطفل أن يترجه بعض الحقائق إلى رسوم تسهل عمليتي التعليه والتعلهم ، وتوضيح الحقائق المراد تعلمها.

وهدف مناهج التربية الفنية ليس تخريج فنانين محترفين يِّ إنتاج الأعمال الفنية ، ولكنها

تهدف إلى تنمية الإحساس بالجمال ، واحترام العمل اليدوي ، كما أن لها دورا أساسيا يِّ جعل

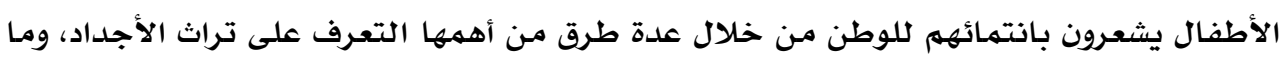
تركوه من أعمال فنية ومبتكرات استخدموها ِيْ حياتهم (Brynigolson,2010,382). وبهذا تمثل تنمية قيم المواطنة لدى الأطفال أحد أهم التحديات الحقيقية التي تواجه

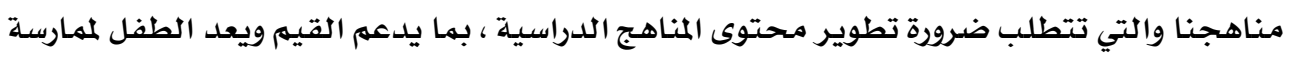

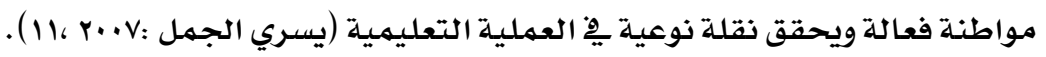
ثانيا: المواطنة.

المواطنـة بشكل بسيط هي انتماء الإنسـان إلى بقعـة أرض، ويقصد بالإنسان كل مـن

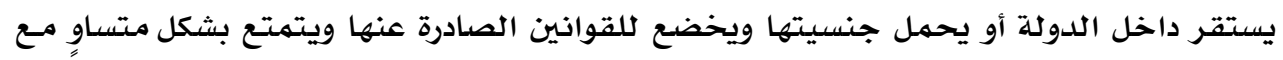

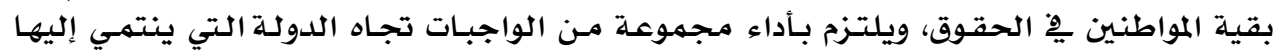

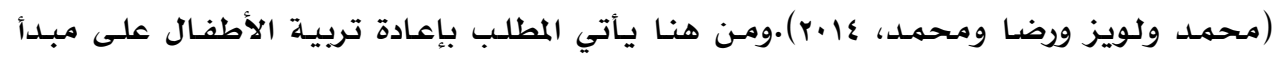

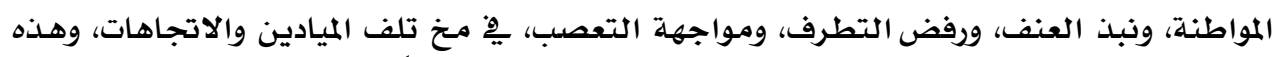

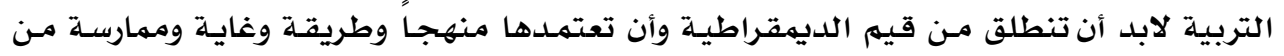

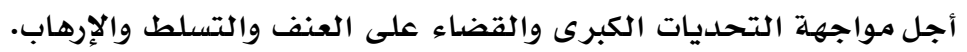

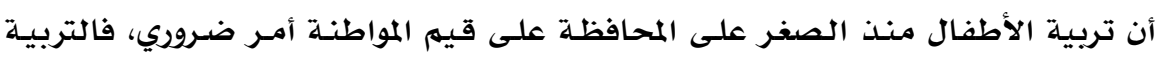

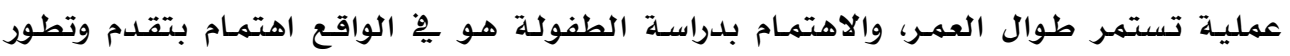

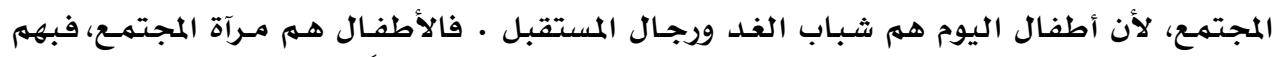

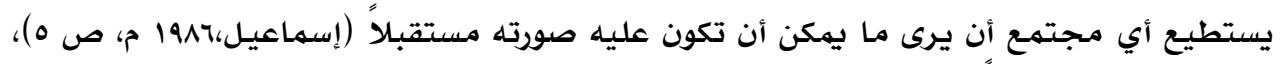

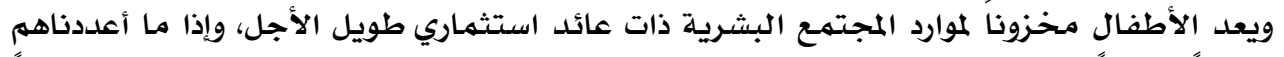

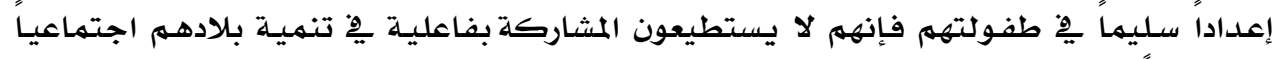

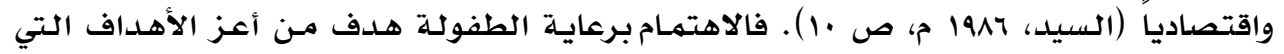

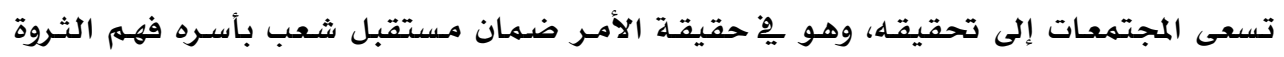

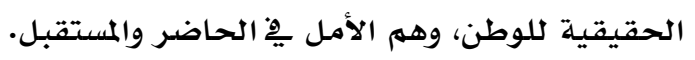


مجلة بحوث التريية النوعية-علد الr - م.rl

وتكتسب المواطنة قيمتها من خلال الرأي الجمعي لجماعة تتبلور هويتها من خلال ظروف حياتية معينة وتكون مقبولة ومعترفا بها، حيث تكون هناك قيم أخلاقية وثقافية يشترك فيها جميع المواطنين، وبذلك فإن قيم المواطنة لا تفرض من الخارج فرضا، فالمواطنة تتمثل يِّ الأفكار التي يعبر بها أعضاء المجتمه عن اهتماماتهم يِّ أسلوب إيجابي يِّ ضوء ضمير وطني يتهم تكوينه من خلال مؤسسات التنشئة التربوية التي تهدف إلى تنشئة المواطن من خلال الأسرة والمدرسة ودور العبادة والجامعة والأندية ومراكز الشباب والجمعيات الأهلية.

\section{قيم الإعاطنة:}

تعد قيم المواطنة من أهم مقومات المجتمـع وتعرف بأنها : مجموعة من القيم التي تعكس انتماء الطالب لوطنه، والوعي بالأمور الوطنية والاجتماعية والاقتصادية والبيئية ،والانفتاح على لماتهي الثقافات الأخرى، واتصافه بالقيه الأخلاقية الحميلدة والمسئواية الاجتماعية تجاه نفسه ومجتمعهد

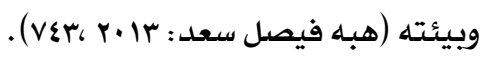

ولقد شغل موضوع القيه اهتما المفكرين والباحثين ،على اختتلاف انتماءاتهم العلمية والايدلوجية يِّ محاولة منهم للكثف عن طبيعة تلك القيم وملامحها وأبعادها ومعايير تصنيفها، ودورها كمتغير لله أهميته يِّ مختلف نواحي الحياة.ومن بين تلك الآراء فيما يتعلق بأبعاد قيم المواطنة ما يلي:

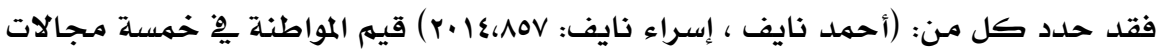
هي: قيم المواطنة السياسية، قيم المواطنة الاقتصادية، قيم المواطنة الثقافية، قيم المواطنة الجمالية، قيم المواطنة الاجتماعية . كئم

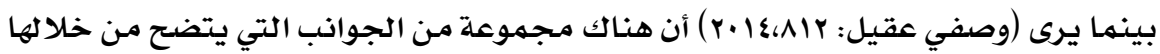
قيه المواطنة وتتمثثل يِ: الجانب الوجداني، الجانب القانوني، الجانب السياسي، الجانب الاجتماعي، الجانب الاقتصادي.

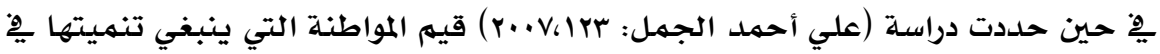

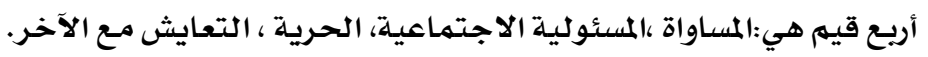

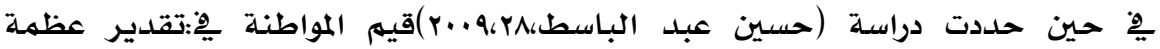

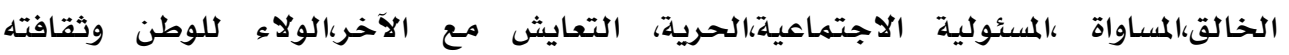

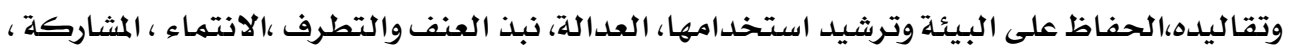
التسامح، الحرية، احترام الملكية العامـة ، حب الوحدة الوطنية . 


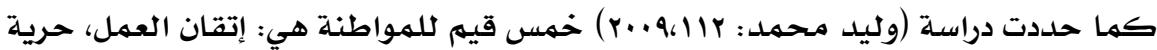
الاعتقاد، تقدير قيمة الوقت، التعاون، مسئولية الفرد عن أعماله.

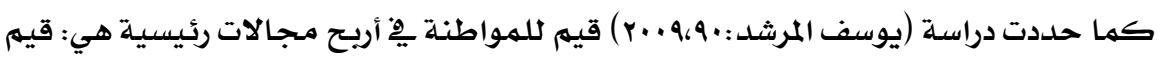
تهدف لخدمة الأمة بشكل عام والوطن بشكل خاص،مستوى العلاقات مـع الآخرين،مجال العمل،المستوى الفردي.

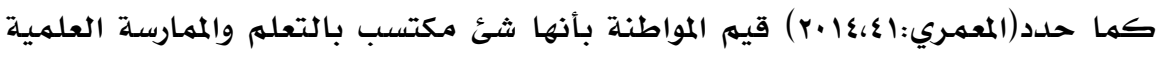
وذلك بالالتزام نحو الدولة ورموزها والمشاركة النشطة لتحقيق التنمية ِِّ المجتمع · وتتكون قيم المواطنة من خمسة أبعاد وهي: قيه المواطنة السياسية، قيم المواطنة الاقتصادية، قيه المواطنة

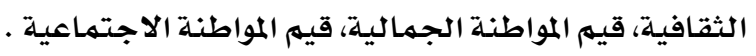

\section{ثالثا: الطفهولة.}

تعتبر مرحلة الطفولة مرحلة مهمة ومتميزة من مـراحل نهو الإنسان، إذ يتم فيها بناء

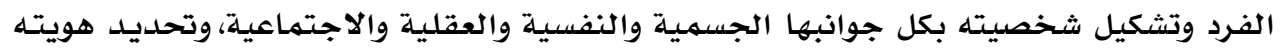

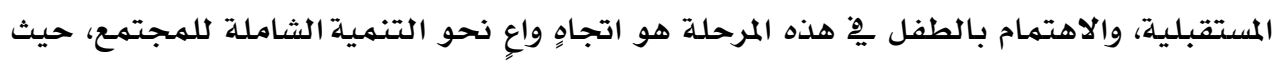

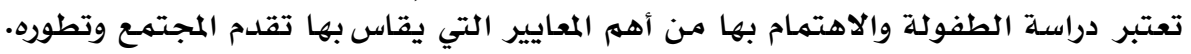
وتعد دراسة الطفولة جزءا هاما من الاهتمام بالحاضر والمستقبل معا حيث يشكل الأطفال

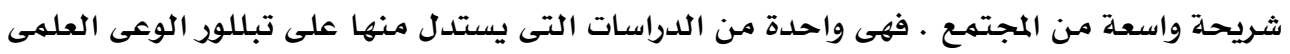

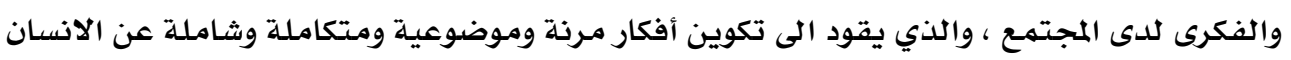

$$
\text { وحاضره ومستقبله. }
$$

يعتبر نهو الطفل عند بياجيه Jean Piaget ( عالم نفس وفيلسوف سويسرى يشتهر

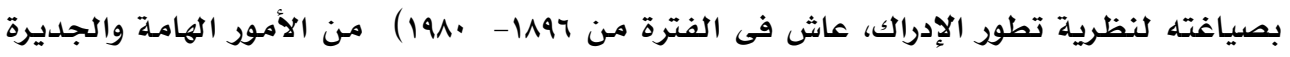

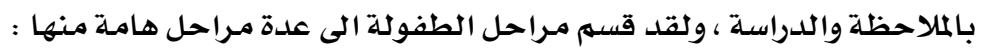

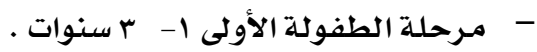

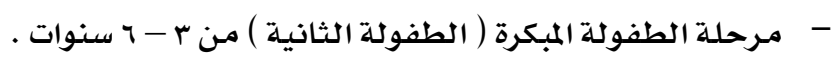

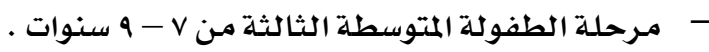

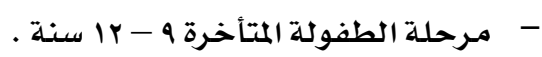

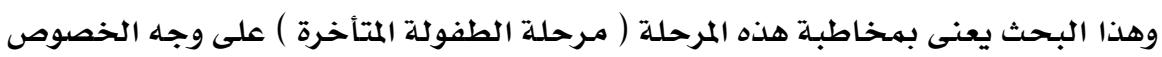

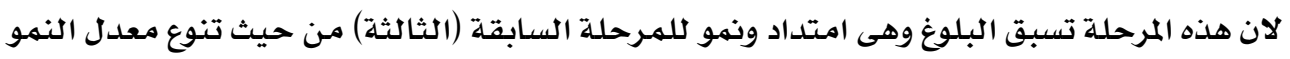

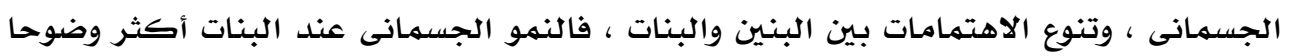

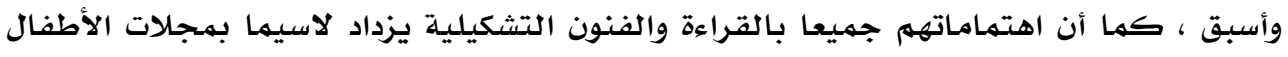


المتتوعة ، والكتب التى لها صلة باهتماماتهم فى هذه المرحلة كالقصص التاريخية، وقصص

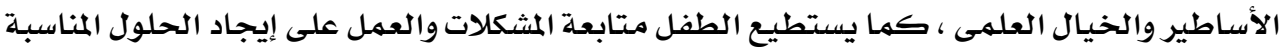

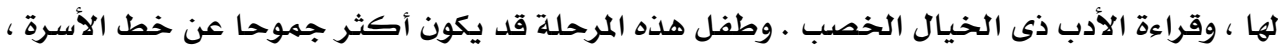

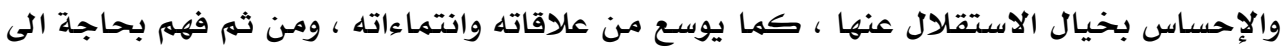

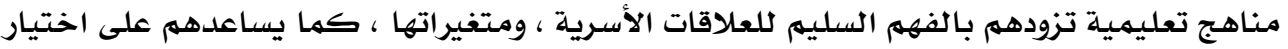

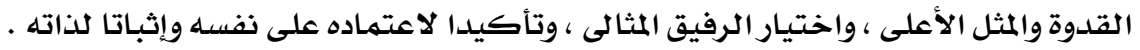

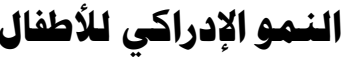

الأسس السيكولوجية إلى تعتمد عليها عملية النمو الإدراكي لدى الأطفال :

1- البعد الوجداني: يتمثل فِ الاتجاهات والميول والدوافع وخصائص الطفل الذاتية والشخصية

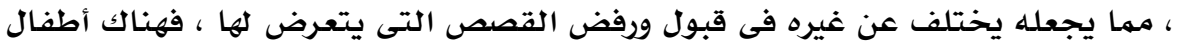

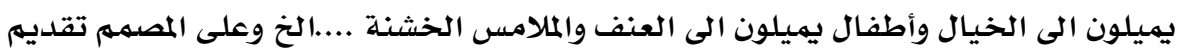

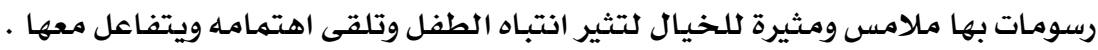
r- البعد الاجتماعي: يتضمن الخلفية الاجتماعية والثقافية للطفل المقدم له النموذج القابل

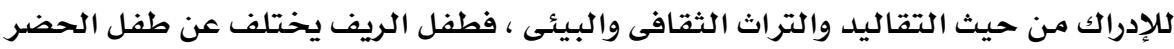

، فلكل طفل نموذجه الخاص الذئى يفهمهـ .

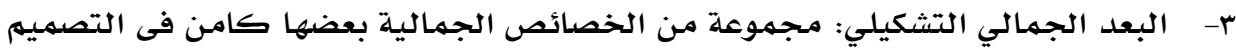

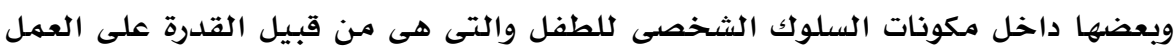

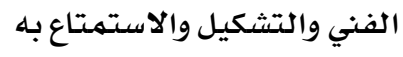

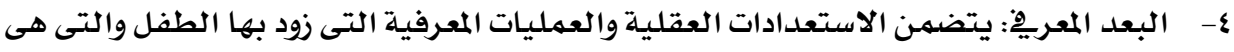

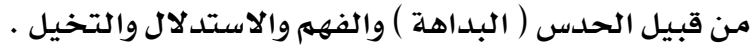

\section{جوانب تطور إدراك الطفل لعناصر الفنون التشكيلية :}

1- إدراك الشكل : من ج- V سنوات يصبح الطفل قادرا على تمييز الحروف الهجائية والأرقام

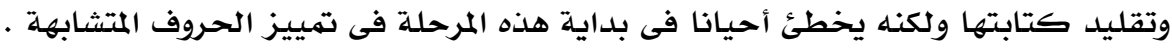

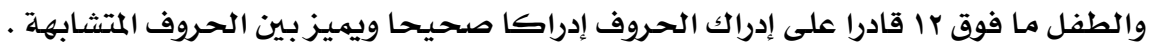

يتعرف على كل ما حوله من الأثكال فشكل الدائرة والمثلث والمربع والمستطيل كلها تمر بحياة

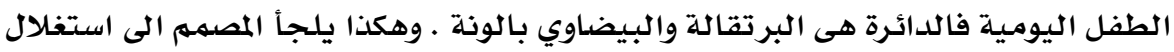

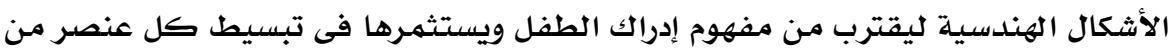

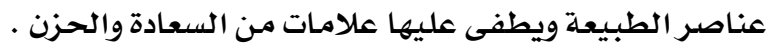

r- اللون : يعتبر اللون هو أول ما يخطف بصر الطفل وهو العامل الرئيسى لجذب التبل انتباهه ،

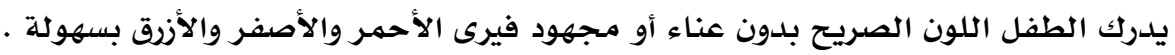


فالطفل الصغير لا يميل الى الرسوم ذات اللونين الأبيض والأسود وإنها اللجوء الى استخدام

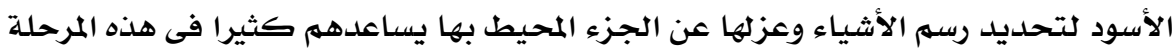

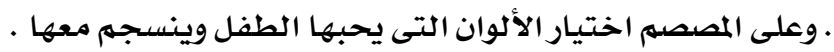

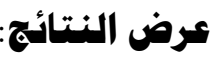

السؤال الأول :

ما قيم المواطنـة التي تسعى منـاهج التربية الفنيـة إلى تنميتها لدى الأطفـال ِِّ مرحلـة

الطفولة المتأخرة ؟

للإجابة على هذا التساؤل تم التوصل الى خمسـة محاور تشكل قيم المواطنة، وهى:

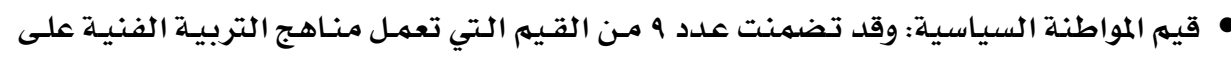

تنميتها.

• قيم المواطنة الاجتماعية: وقد تضمنت عدد 17 من القيم التي تعمل مناهج التربية الفنية على تصى

تنميتها.

• قيهم المواطنـة الاقتصادية: وقد تضمنت عدد ^ من القيم التي تعمل منـاهج التربيـة الفنيـة على

تنهيتها.

• قيم المواطنـة الجماليـة: وقد تضمنت عدد 9 مـن القـيم التي تعمل منـاهج التربيـة الفنيـة على

تنهيتها.

• قيهم المواطنـة التربويـة: وقـد تضهنت عدد ^ مـن القـيم التي تعمـل منـاهج التربيـة الفنيـة على

تنميتها.

السؤال الثاني :

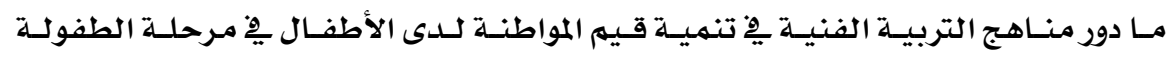

المتأخرة ؟ - n

للإجابة على هذا التساؤل من خلال استجابات أفراد العينة، وكانت كما يلي:

خصائص أفراد عينة البحث.

المؤهل الدراسي

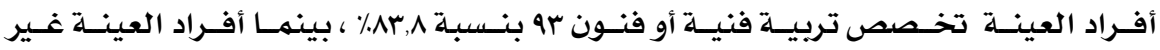

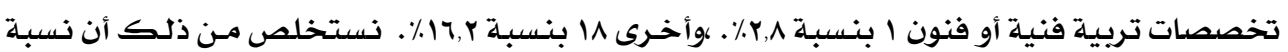

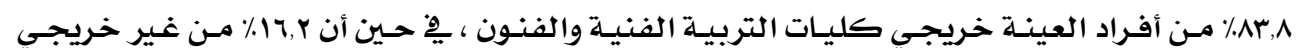

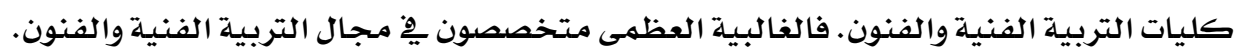
سنوات الخبرة : 


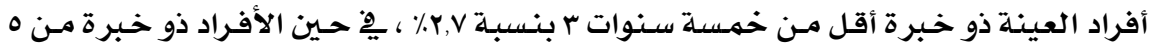

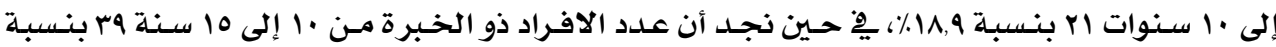

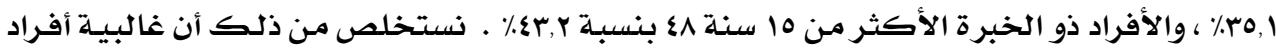

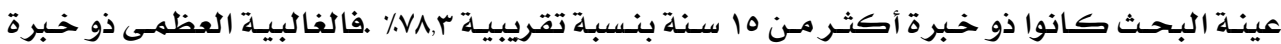
علمية

\section{ا ـ قيم المواطنة السياسية:}

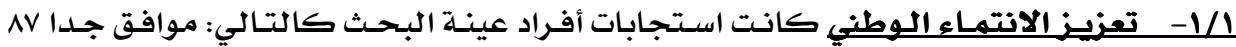

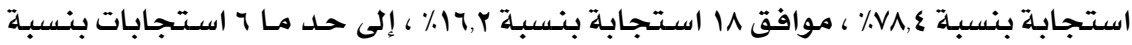

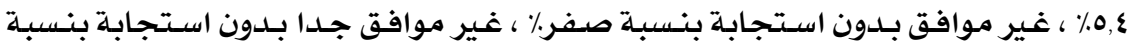

$$
\text { صفر. }
$$

نستخلص من تلك الاستجابات ، أن متوسط استجابات أفراد العينة كانت بنسبة ؟ ؟ 9٪٪.

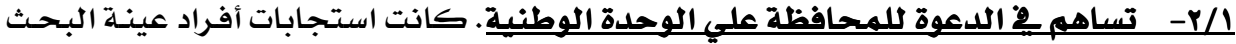

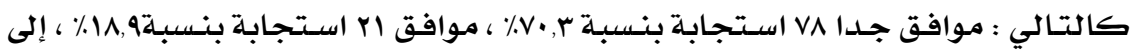

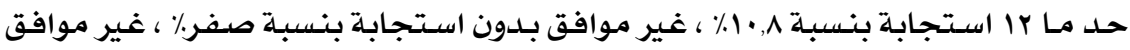

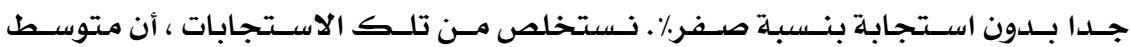

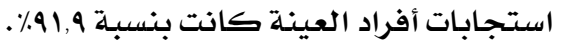

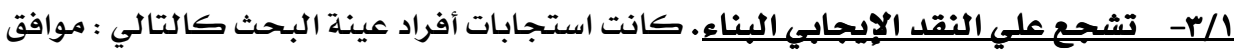

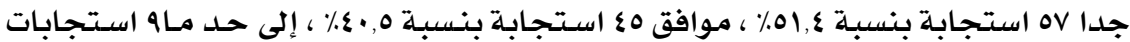

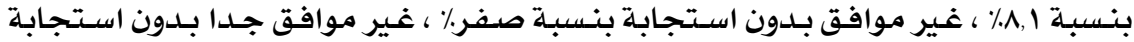

$$
\text { بنسبـة صفر٪ }
$$

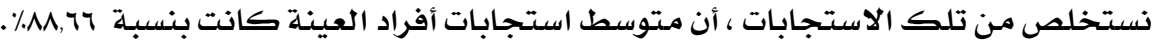
1/ع- عزيز الهوية الوطنية والارتباط بالوطن. كانت استجابات أفراد عينة البحث كالتالي :

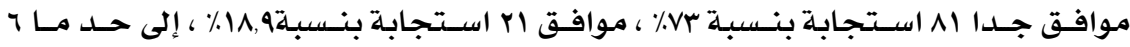

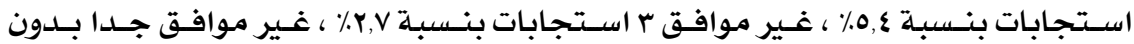
استجابة بنسبة صفر٪

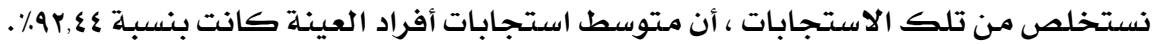

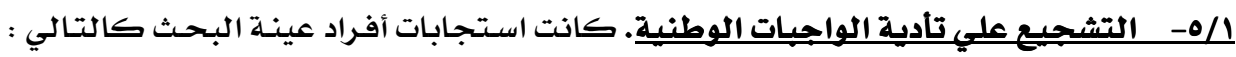

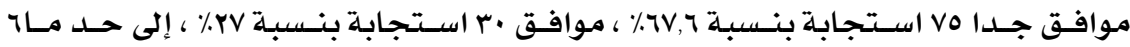

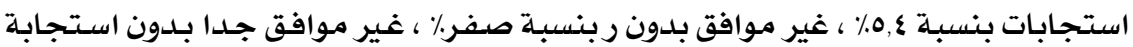

$$
\text { بنسبـة صفر٪\% }
$$

نستخلص من تلك الاستجابات ، أن متوسط استجابات أفراد العينة كانت بنسبة ؟؟ ؟ ؟ ٪. 


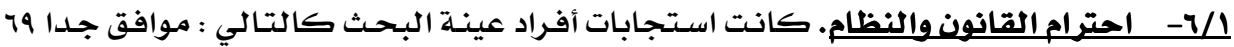

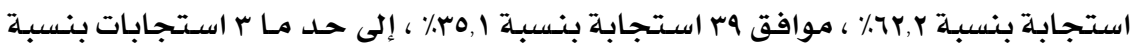

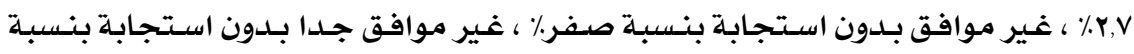

$$
\text { صفر. }
$$

نستخلص من تلك الاستجابات ، أن متوسط استجابات أفراد العينة كانت بنسبـة 9, 91٪.

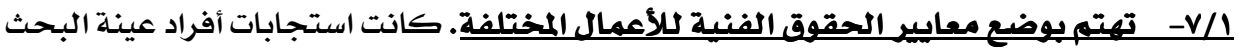

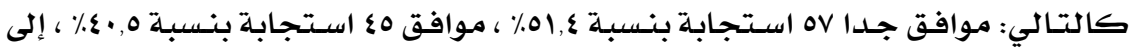

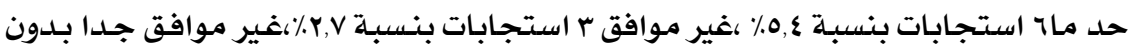

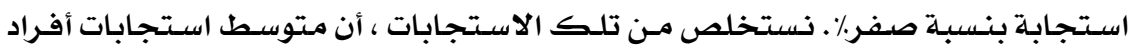

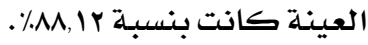

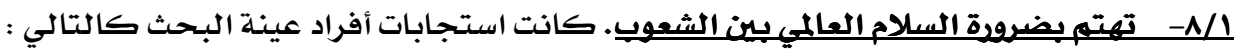

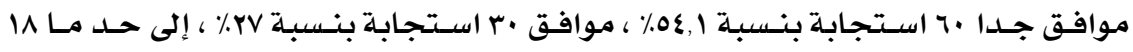

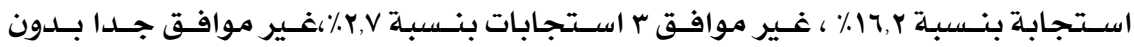

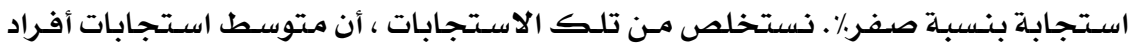

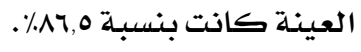

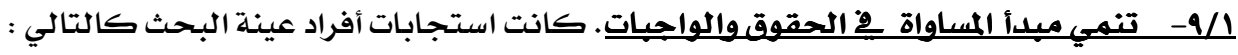

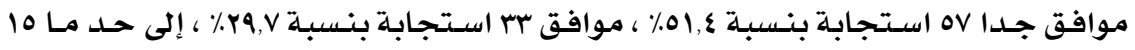

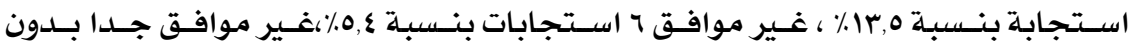

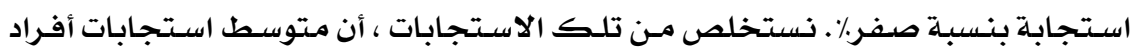

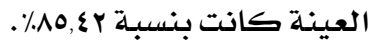

\begin{tabular}{|c|c|c|c|c|c|c|c|c|c|}
\hline متوسط & 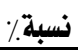 & 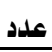 & 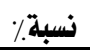 & 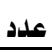 & 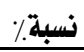 & 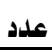 & 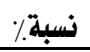 & 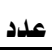 & 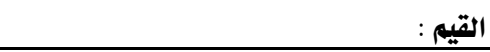 \\
\hline $9 \xi, \uparrow$ & - & - & $0, \S$ & 1 & $17, r$ & 11 & $\forall \wedge, \varepsilon$ & Av & تمزيز الاتتماء الوطني \\
\hline $9 r,\lfloor\xi$ & $r, r$ & $r$ & $0, \S$ & 1 & 11,9 & ri & vr & $\wedge 1$ & تعزيز الهوية الوطنية والارتباط بالوطن. \\
\hline $9 r,\lfloor\xi$ & - & - & $0, \xi$ & 9 & rr & r. & IY, & vo & التشجيع علي تأدية الواجبات الوطنية. \\
\hline 91,9 & - & - & $1 \cdot, 1$ & ir & $1 \mathrm{~A}, 9$ & ri & $r \cdot, r$ & YA & تساهم في اللدعوة للمحافظة علي الوحلدة الوطنية \\
\hline 91,9 & - & - & $r, r$ & $r$ & ro,1 & rq & $7 r, r$ & 79 & احترام القانون والنظام \\
\hline$\wedge \Lambda, 77$ & $\cdot$ & - & $\Lambda, 1$ & 9 & $\xi \cdot, 0$ & §o & $01, \xi$ & or & تشجع علي النقد الإيجابي البناء. \\
\hline$\wedge \Lambda, I r$ & $r, r$ & $r$ & $0, \xi$ & 1 & $\xi \cdot, 0$ & §o & $01, \varepsilon$ & or & تهتم بوضع معايير الحقوق الفنية للأعمال المختلفة. \\
\hline$\wedge 9,0$ & $r, r$ & $r$ & $17, r$ & M & rr & $r \cdot$ & $0\}, 1$ & 7. & تهتم بضرورة السلام العالمي بين الشعوب. \\
\hline$\wedge 0, \& \mathrm{r}$ & $0, \xi$ & 1 & $1 r, 0$ & 10 & $r q, r$ & rr & $01, \varepsilon$ & or & تنمي مبلدأ المساواة في الحقوق والواجبات. \\
\hline
\end{tabular}

جدول رقم (1) يوضح ترتيب عدد استجابات والنسبة المئوية والمتوسط الحسابي لأفراد العينة. 
من خلال النتائج السابقة والموضحة يِّ الجدول رقم (1) يمكن ترتيب قيم المواطنسة السياسـة

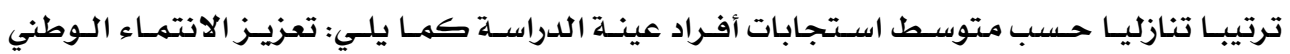

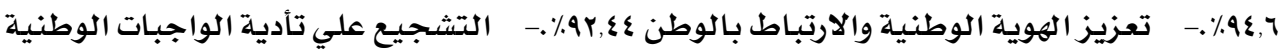

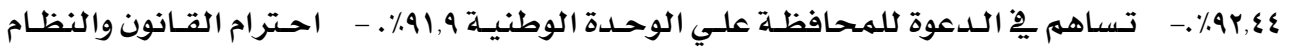

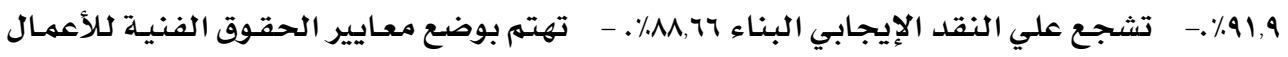

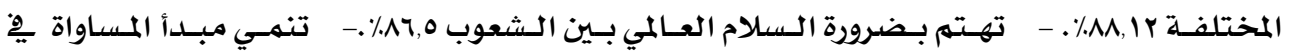

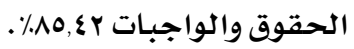

\section{r. قيم المواطنة الاجتماعية:}

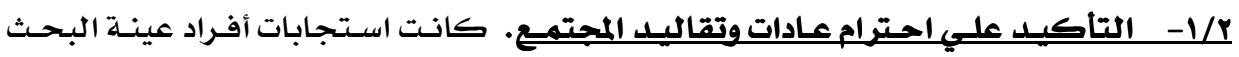

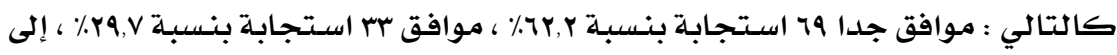

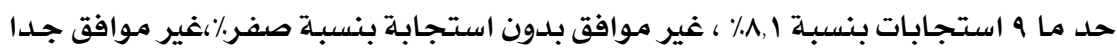
بدون استجابة بنسبة صفر٪

نستخلص من تلك الاستجابات ، أن متوسط استجابات أفراد العينة كانت بنسبة ץ ب, • ٪٪.

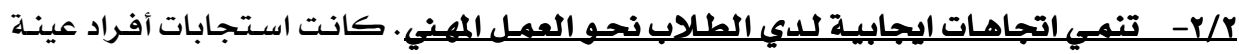

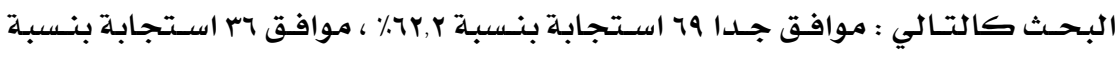

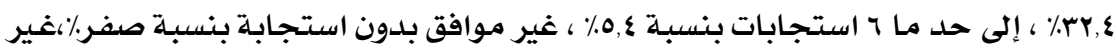

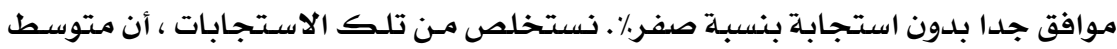

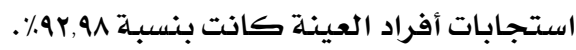

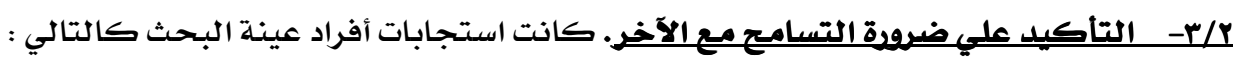

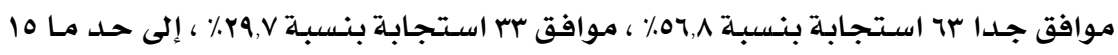

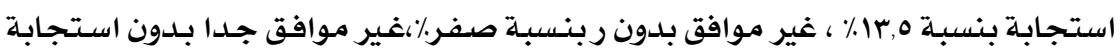
بنسبة صفر٪\%

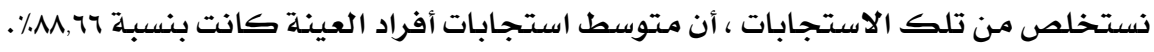

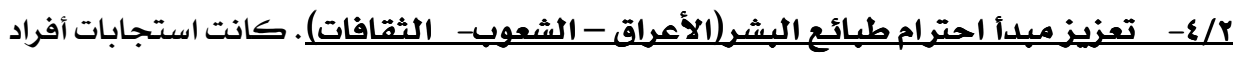

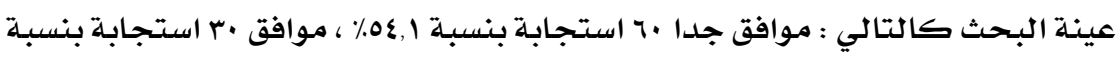

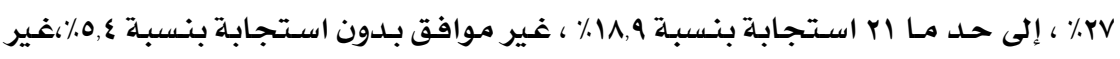

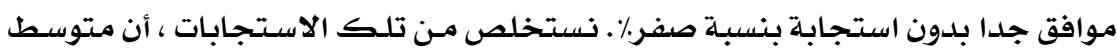

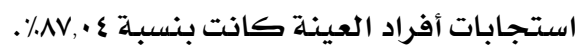

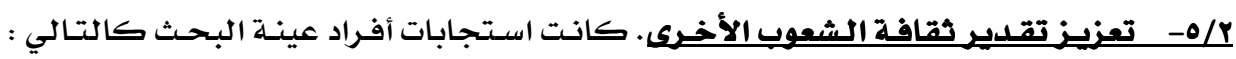

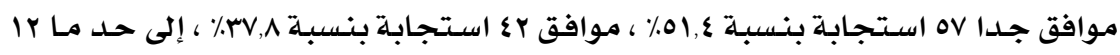


استجابة بنسبة ^, • 1٪ ، غير موافق بـدون استجابة بنسبـة صفر٪٪، غير موافق جـدا بـدون استجابة بنسبـة صفر٪٪

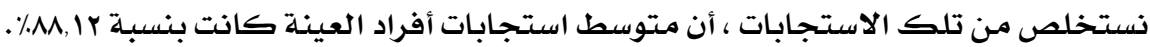

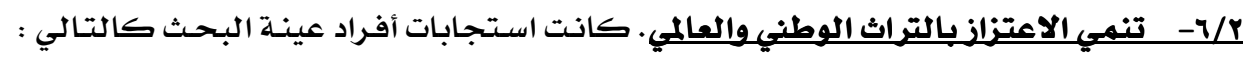

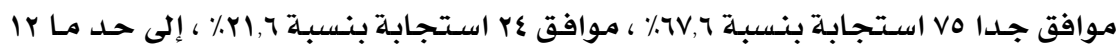

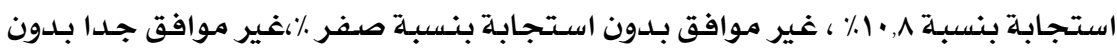
استجابة بنسبـة صفر٪٪

نستخلص من تلك الاستجابات ، أن متوسط استجابات أفراد العينة كانت بنسبة جr, ه1٪.

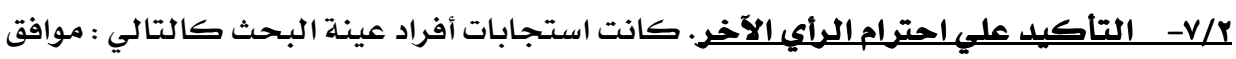

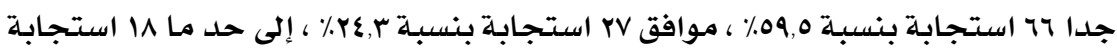

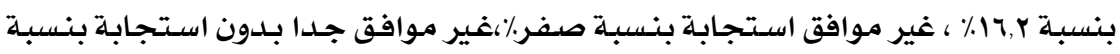

$$
\text { صفر. }
$$

نستخلص من تلك الاستجابات ، أن متوسط استجابات أفراد العينة كانت بنسبة 14.14٪.

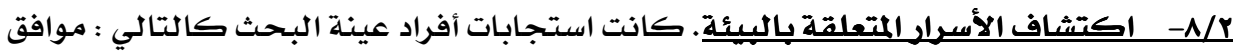

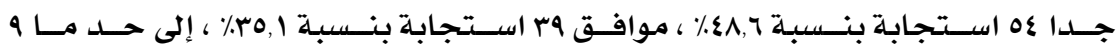

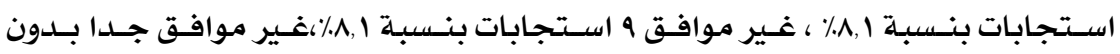

$$
\text { استجابة بنسبـة صفر٪ات }
$$

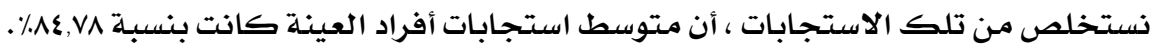

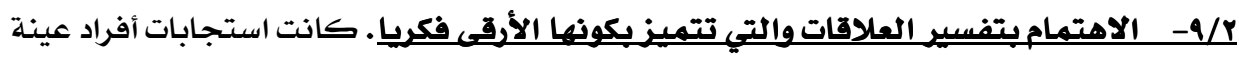

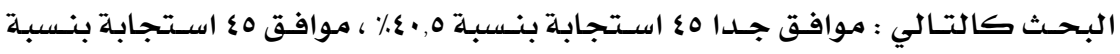

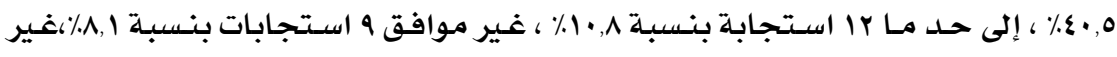

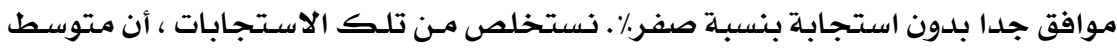

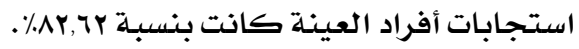

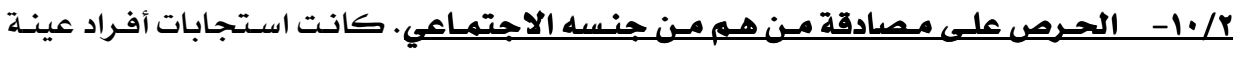

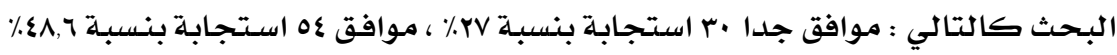

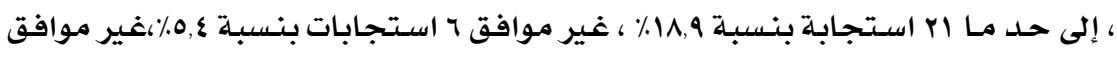

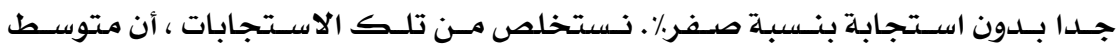

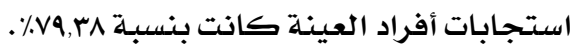

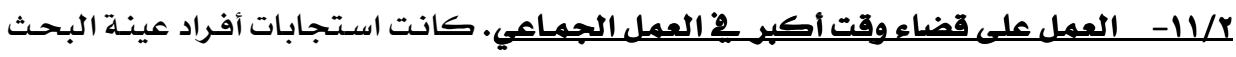

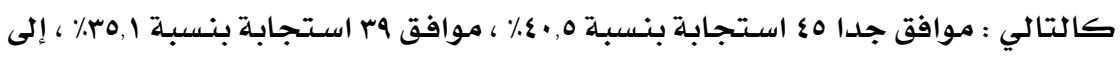

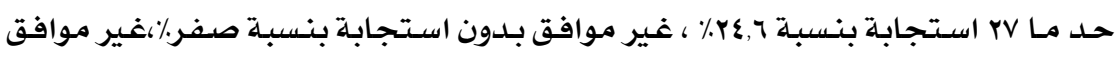


-

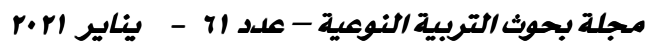

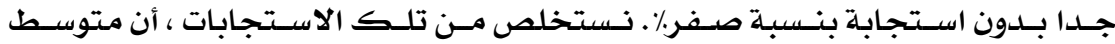

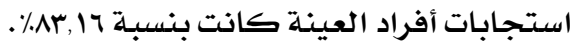

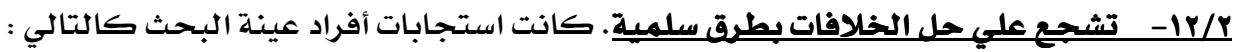

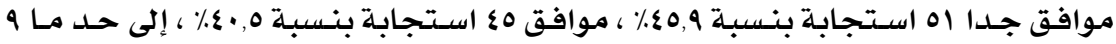

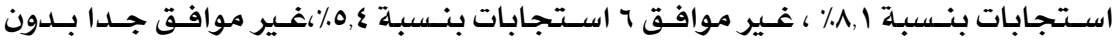
استجابة بنسبـة صفر ٪

نستخلص من تلك الاستجابات ، أن متوسط استجابات أفراد العينة كانت بنسبة بr.10,٪٪. r/r/r ا التأكيد علي حل المشكلات بالحوار الهادف بـين الطلاب. كانت استجابات أفراد عينـة

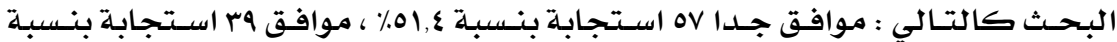

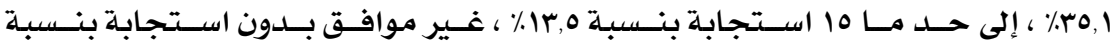

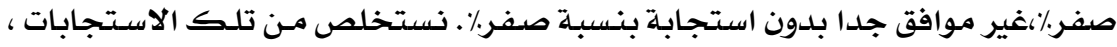

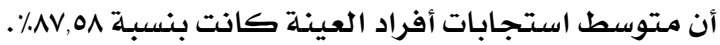

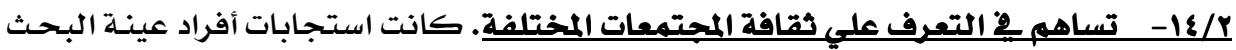

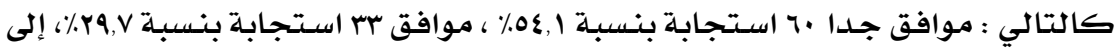

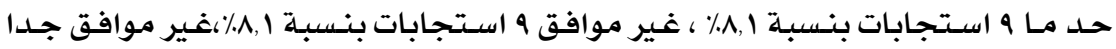
بدون استجابة بنسبة صفر٪

نستخلص من تلك الاستجابات ، أن متوسط استجابات أفراد العينة كانت بنسبة ه0,97٪.

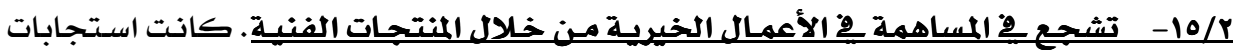

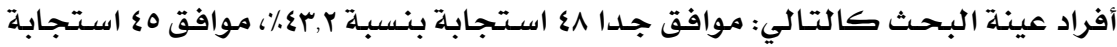

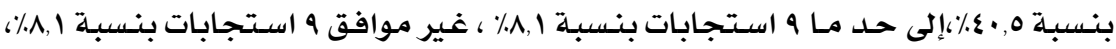

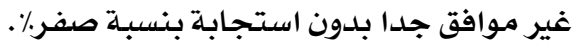
نستخلص من تلك الاستجابات ، أن متوسط استجابات أفراد العينة كانت بنسبـة Vr,v٪.

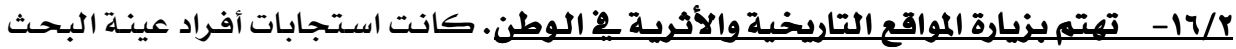

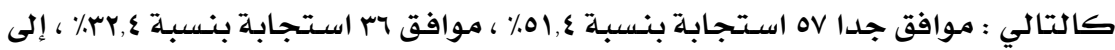

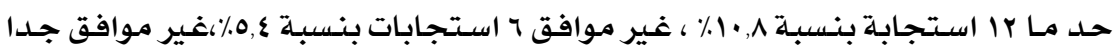
بدون استجابة بنسبة صفر٪ نستخلص من تلك الاستجابات ، أن متوسط استجابات أفراد العينـة كانت بنسبـة 90,1^٪.

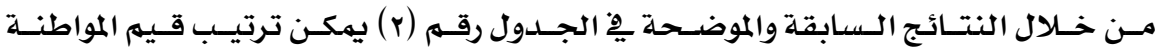

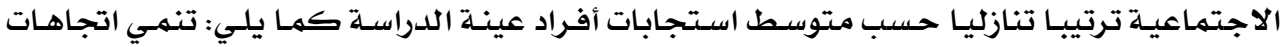

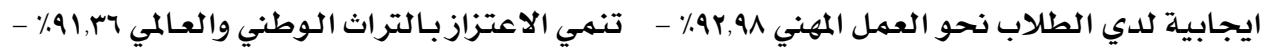

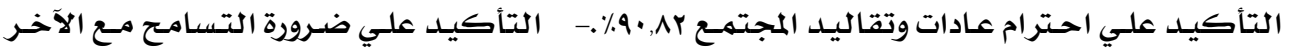




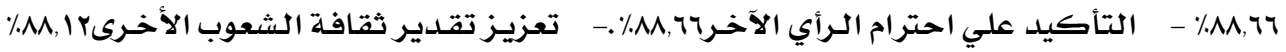

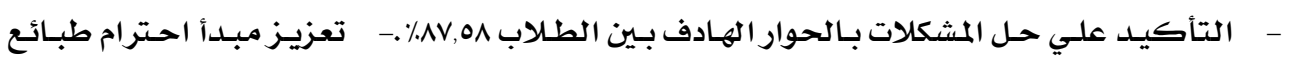

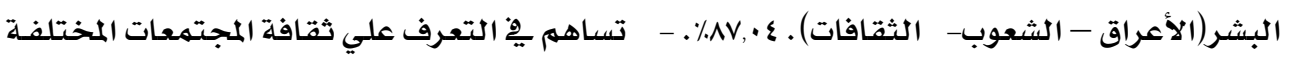

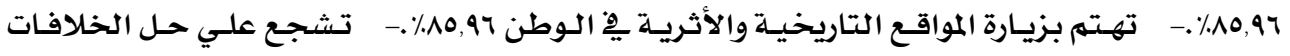

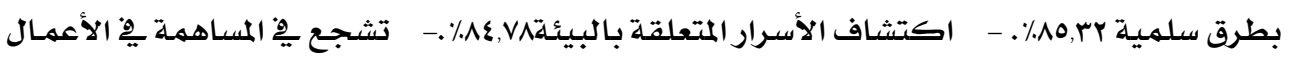

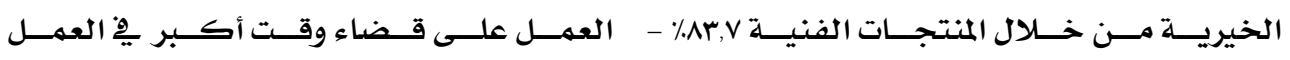

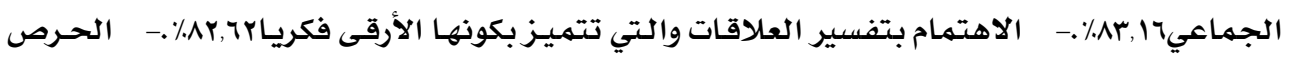

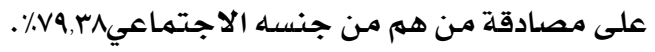

جدول رقم (r) يوضح ترتيب عدد استجابات والنسبة المئوية والمتوسط الحسابي لأفراد العينة.

\begin{tabular}{|c|c|c|c|c|c|c|c|c|c|}
\hline 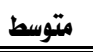 & نسبة. & 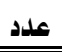 & نسبة. & 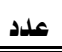 & نسبة. & 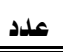 & 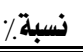 & عدد عد & 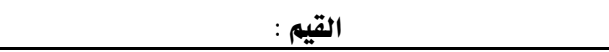 \\
\hline $9 \mathrm{9r}, 91$ & - & - & $0, \xi$ & 9 & $r r, \xi$ & ry & ar, r & 79 & تنمي اتجاهات ايجابية للدي الطلاب نحو العمل المهني \\
\hline $9 \cdot, \wedge r$ & - & - & $\wedge, 1$ & 9 & $r q, Y$ & rr & ar, r & 79 & التأكيد علي احترام عادات وتقاليد المجتمع. \\
\hline А^, 7$\rceil$ & - & - & 17,0 & 10 & $r q, Y$ & rr & $07, \wedge$ & ar & التأكيد علي ضرورة التسامح مع الاخر. \\
\hline$\Lambda \Lambda, I r$ & - & - & $1 \cdot, 1$ & ir & $r v, \Lambda$ & $\xi r$ & $01, \xi$ & or & تعزيز تقدير ثقافة الشعوب الأخرى. \\
\hline$\wedge \vee, \Delta \wedge$ & $\cdot$ & - & $1+0$ & 10 & ro,1 & rq & $01, \xi$ & or & القأكيد علي حل المشكلات بالحوار الهادف بين الطلاب. \\
\hline$\wedge \mathrm{V}, \cdot \varepsilon$ & - & - & 11,9 & M & rr & $r \cdot$ & $0 \leqslant, 1$ & 7. & تعزيز مبدأ احترام طبائع البشر(الاعراق/الشعوب/الثقافات). \\
\hline$\wedge 0,97$ & $\wedge, 1$ & 9 & $\Lambda, 1$ & 9 & $r q, Y$ & rr & $0\}, 1$ & 7. & تساهم في التعرف علي ثقافة المجتمعات المختلفة. \\
\hline$\wedge \varepsilon, \vee \wedge$ & $\wedge, 1$ & 9 & $\wedge, 1$ & 9 & ro,1 & rq & $\{\Lambda\rceil$, & os & اكتشاف الأسرار المتعلقة بالبيئة. \\
\hline$\wedge r, \mathrm{r}$ & $\wedge, 1$ & 9 & $\Lambda, 1$ & 9 & $\xi \cdot, 0$ & §o & $\xi r, r$ & $\xi \wedge$ & تشجع في المساهمة في الاعمال الخيرية من خلال المنتجات الفنية \\
\hline Ar, 17 & $\cdot$ & - & $r \xi, r$ & rv & ro,1 & rq & $\xi \cdot, 0$ & §o & العمل على قضاء وقت أكبر في العمل الجماعي. \\
\hline Ar, Ir & $\wedge, 1$ & 9 & $1 \cdot, 1$ & ir & $\xi \cdot, 0$ & §o & $\xi \cdot, 0$ & §o & الاهتمام بتفسير العلاقات والتي تتميز بكونها الارقي \\
\hline va, rA & $0, \xi$ & 9 & 11,9 & rl & $\{\wedge\rceil$, & os & rr & r. & الحرص على مصادقة من هم من جنسه الاجتماعي. \\
\hline
\end{tabular}

r. قيم المواطنة الاقتصادية:

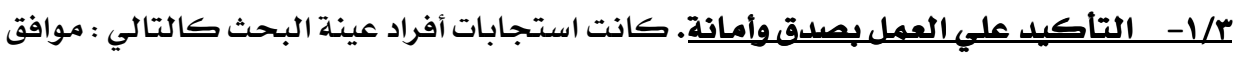

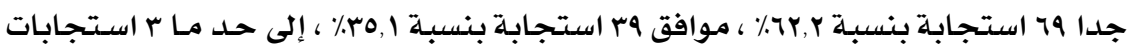

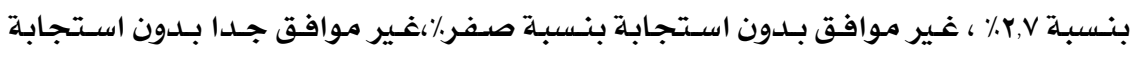

$$
\text { بنسبة صفر٪\% }
$$

نستخلص من تلك الاستجابات ، أن متوسط استجابات أفراد العينـة كانت بنسبـة 919\%. 


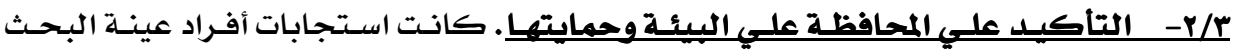

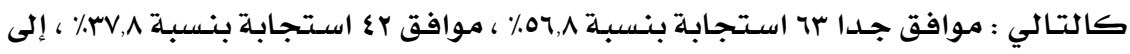

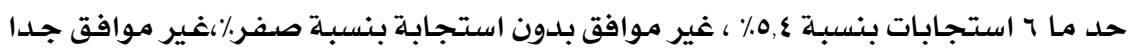
بدون استجابة بنسبـة صفر٪

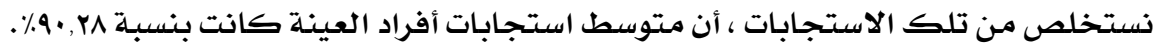

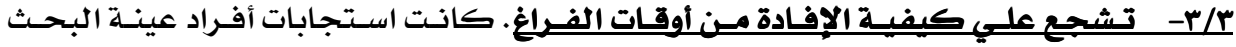

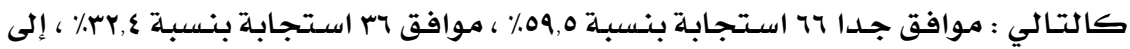

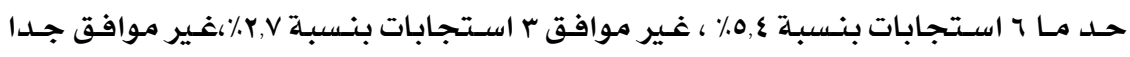
بدون استجابة بنسبة صفر٪

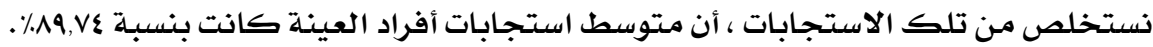

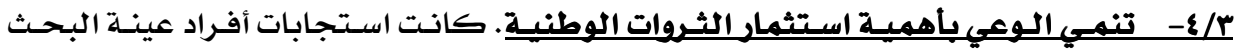

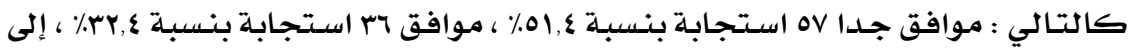

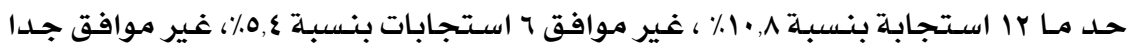
بدون استجابة بنسبة صفر٪

نستخلص من تلك الاستجابات ، أن متوسط استجابات أفراد العينة كانت بنسبـة 10,97٪.

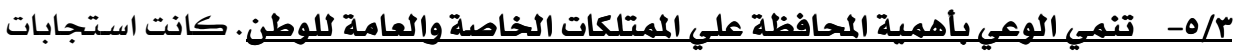

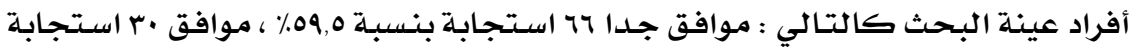

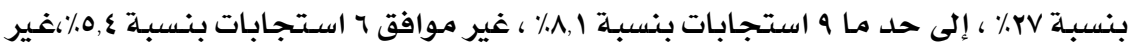

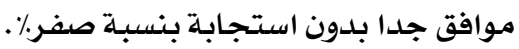

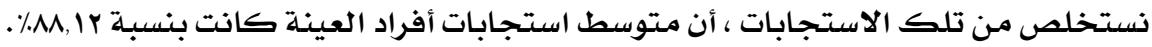

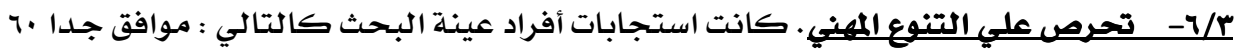

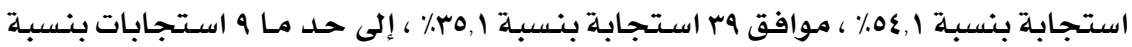

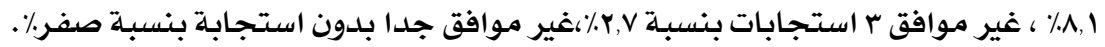

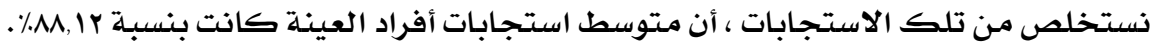

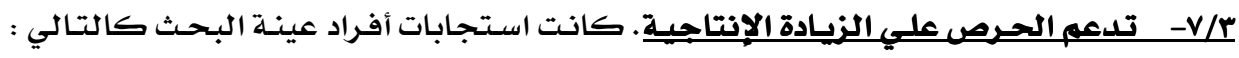

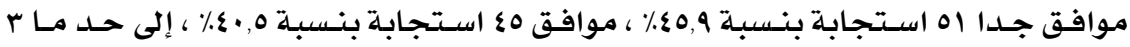

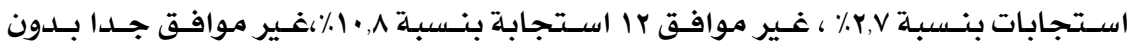

$$
\text { استجابة بنسبـة صفر٪٪ }
$$

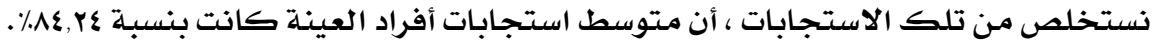
ب/^- تبرز أهمية استخدام التفكير العملي عند ممارسة الأعمال الفنية. كانت استجابات أفراد

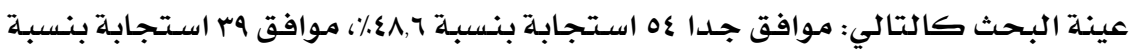




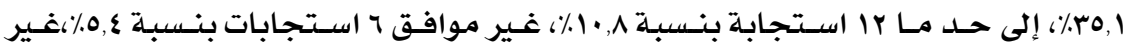

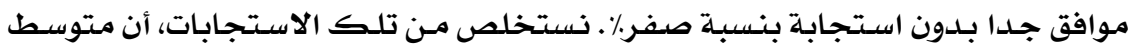

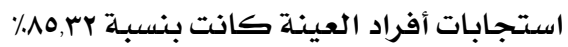

جدول رقم (r) يوضح ترتيب عدد استجابات والنسبة المئوية والمتوسط الحسابي لأفراد العينة.

\begin{tabular}{|c|c|c|c|c|c|c|c|c|c|}
\hline متوسط & 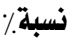 & علد عد & 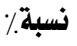 & 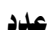 & 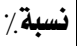 & 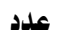 & 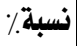 & 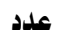 & 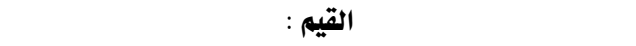 \\
\hline 91,9 & - & - & $r, r$ & $r$ & ro,1 & rq & $\pi r, r$ & 79 & التأكيد علي العمل بصدق وأمانة. \\
\hline $9 \cdot, \mathrm{rA}$ & - & - & $0, \xi$ & 1 & $r v, \Lambda$ & $\xi r$ & 07,1 & $9 r$ & التأكيد علي المحافظة علي البيئة وحمايتها. \\
\hline$\wedge 9, \vee 乏$ & $r, \mathrm{r}$ & r & $0, \xi$ & 1 & $r r, \xi$ & $r q$ & 09,0 & 79 & تشجع علي كيفية الإفادة من أوقات الفراغ. \\
\hline$\Lambda A, I r$ & $0, \varepsilon$ & 9 & $\Lambda, 1$ & 9 & rv & r. & $\Delta 9,0$ & 97 & تنفي الوعي بأهية المحافظة علي الممتلكات الخاصة والعامة للوطز. \\
\hline$\Lambda \Lambda, I T$ & $r, r$ & r & $\Lambda, 1$ & 9 & ro, 1 & rq & $0 \leqslant, 1$ & 7. & تحرص علي التنوع المهني. \\
\hline$\wedge 0,97$ & $0, \varepsilon$ & 9 & $1 \cdot, 1$ & ir & $r r, \xi$ & rq & $01, \xi$ & or & تنمي الوعي بأهمية استئمار الثروات الوطنية. \\
\hline A0,rr & $0, \varepsilon$ & 1 & $1 \cdot, 1$ & ir & ro,1 & rq & $\{\wedge, 7$ & os & تبرز أهمية استخلام التفكير العملي عند ممارسة الأعمال الفنية. \\
\hline$\Lambda \xi, r \xi$ & $1 \cdot, 1$ & ir & $r, \mathrm{r}$ & $r$ & $\xi \cdot, 0$ & so & $\S 0,9$ & 01 & تلدعم الحرص علي الزيادة الاتتاجية. \\
\hline
\end{tabular}

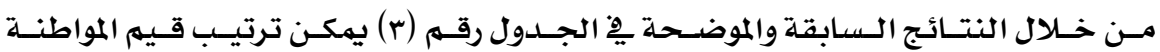

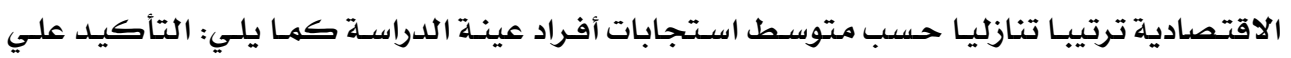

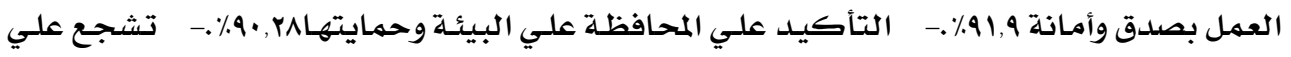

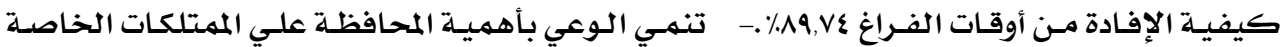

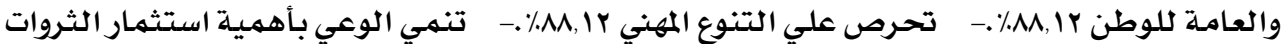

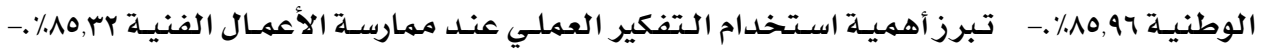

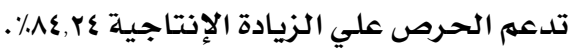

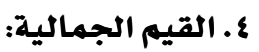

ع/1 التأكيد علي اكتساب المعرفة الجلديدة مـن خـلال الأنشطة الفنيـة. كانت استجابات

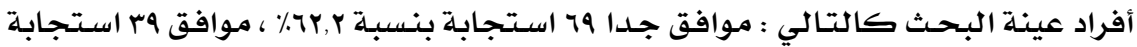

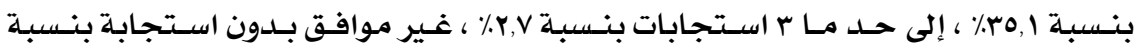

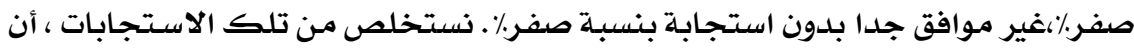

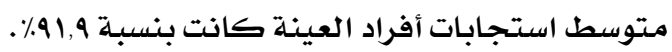

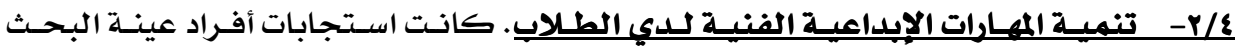

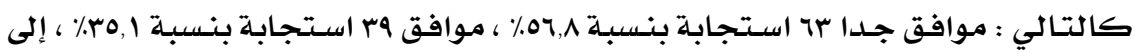

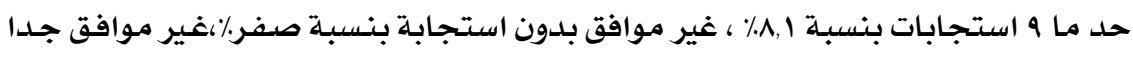
بدون استجابة بنسبة صفر

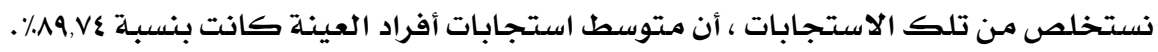


ב-2 مجلة بحوث التربية النوعية - علد r.rl

ع/r- التشجيع علي استخدام التفكير النقد الفني كلأعمال الفنية المختلفة. كانت استجابات

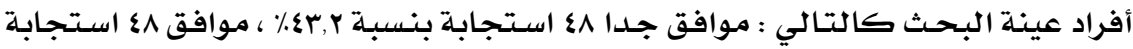

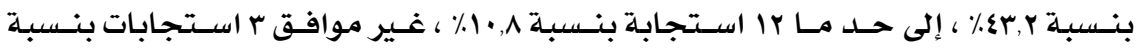

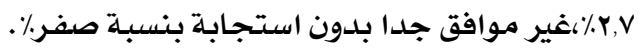

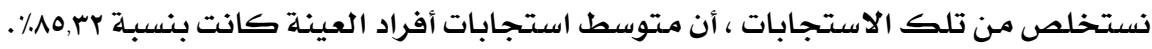

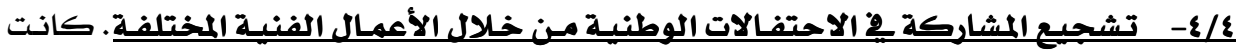

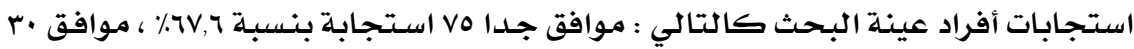

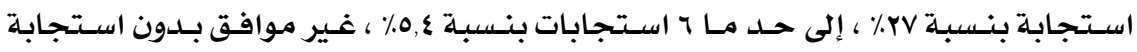

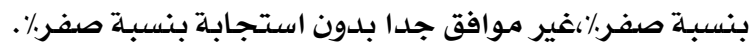

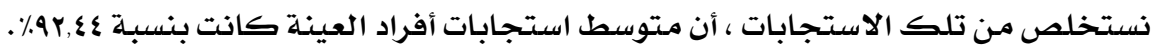
ع/ه- التأكيد علي التزام بـالمظهر الخـارجي الـوطني الإيجابي. كانت استجابات أفراد عينـة

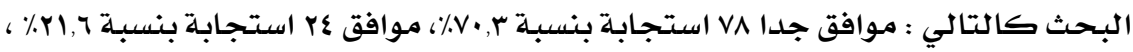

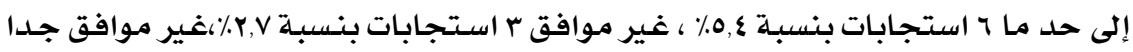
بدون استجابة بنسبة صفر٪

نستخلص من تلك الاستجابات ، أن متوسط استجابات أفراد العينـة كانت بنسبـة 91، .

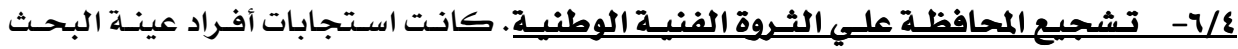

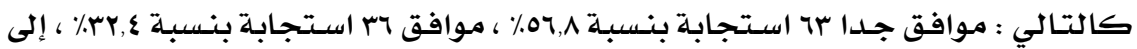

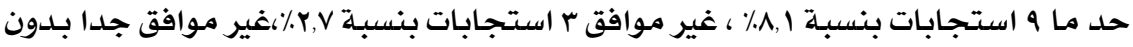
استجابة بنسبـة صفر٪

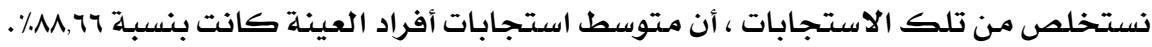

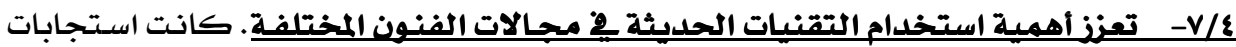

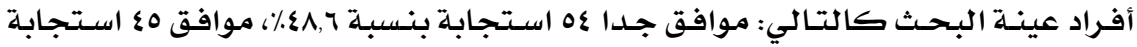

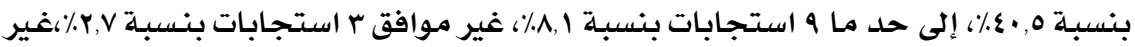

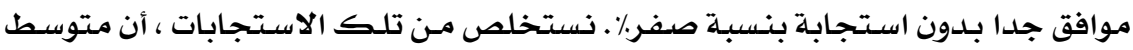

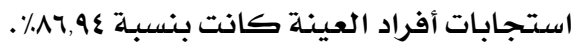

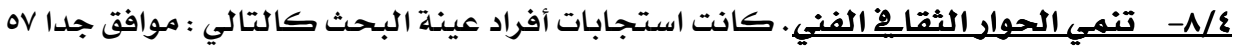

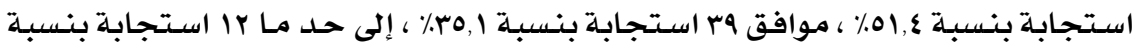

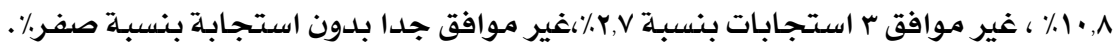

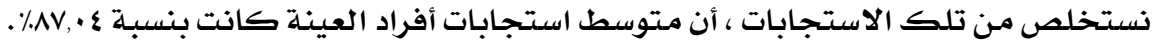

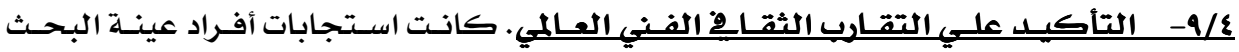

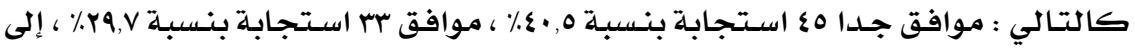




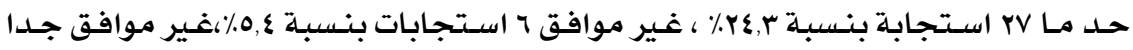

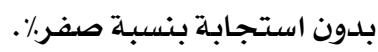

نستخلص من تلك الاستجابات ، أن متوسط استجابات أفراد العينة كانت بنسبة ایه٪.

جدول رقم (§) يوضح ترتيب عدد استجابات والنسبة المئوية والمتوسط الحسابي لأفراد العينة.

\begin{tabular}{|c|c|c|c|c|c|c|c|c|c|}
\hline 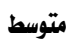 & 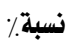 & علد & 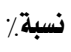 & عدد & 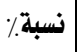 & عدد & 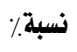 & عدد & 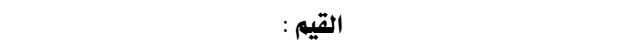 \\
\hline ar, ¿\& & - & - & $0, \xi$ & 9 & rv & r. & $7 v, 7$ & vo & تشجيع الششاركة في الاحتفالات الوطنية من خلال الأعمال الفنية المختلفة. \\
\hline 91,9 & . & - & $r, r$ & $r$ & ro,1 & ra & $m, r$ & 79 & التأكيد علي اكتساب المعرفة الجديدة من خلال الأنشطة الفنية. \\
\hline 91,9 & $r, r$ & $r$ & $0, \xi$ & 9 & $r, q$ & r६ & $r \cdot, r$ & va & التأكيد علي التزام بالمظهر الخارجي الوطني الإيجابي. \\
\hline$\wedge 9, \vee \xi$ & - & - & $\Lambda, 1$ & 9 & ro,1 & rq & $\Delta 7,1$ & $\pi$ & تنمية الهارات الإبداعية الفنية لدي الطلاب. \\
\hline$\wedge \Lambda, 77$ & $r, r$ & $r$ & $\Lambda, 1$ & 9 & $r r, \varepsilon$ & rq & $\Delta 7, \Lambda$ & $\pi$ & تشجيع المحافظة علي الثروة الفنية الوطنية. \\
\hline$\Delta v, \cdot \xi$ & $r, r$ & $r$ & $1 \cdot, 1$ & ir & ro,1 & ra & $01, \xi$ & or & 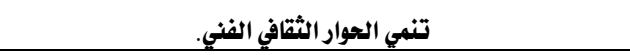 \\
\hline$\wedge \uparrow, ৭ \xi$ & $r, r$ & $r$ & $\Lambda, 1$ & 9 & $\varepsilon \cdot, 0$ & §o & $\{\wedge, \uparrow$ & ه & تعزز أهية أستخدم التقنيات الحديثة في مجالات الفنون المختلفة. \\
\hline Ao,rr & $r, r$ & $r$ & $1 \cdot, 1$ & ir & $\varepsilon r, r$ & $\varepsilon \wedge$ & $\varepsilon r, r$ & $\varepsilon \wedge$ & التشجيع علي استخدام التفكير النقد الفني للأعمال الفنية المختلفة. \\
\hline AI & $0, \xi$ & 9 & $r \xi, r$ & rv & $r q, r$ & rr & $\xi \cdot, 0$ & §o & التأكيل علي التقارب الثقافي الفني العالمي. \\
\hline
\end{tabular}

من خلال النتائج السابقة والموضحة يِّ الجدول رقم (ع ) يمكن ترتيب قيم المواطنة الجمالية

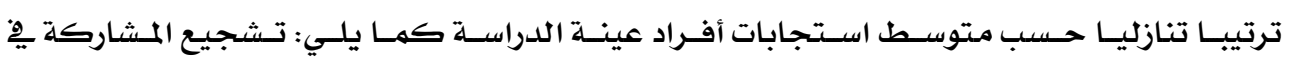

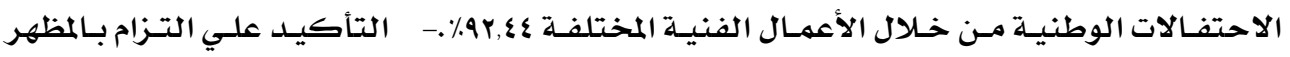

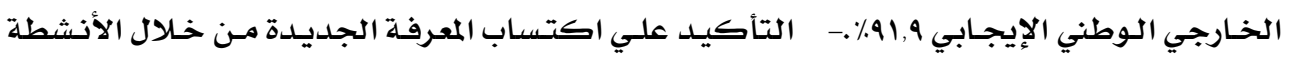

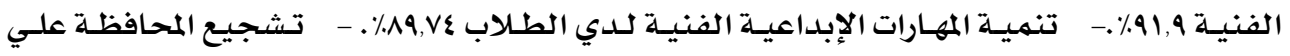

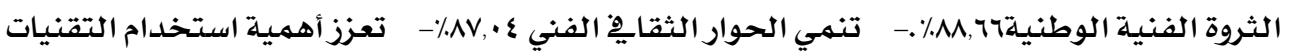

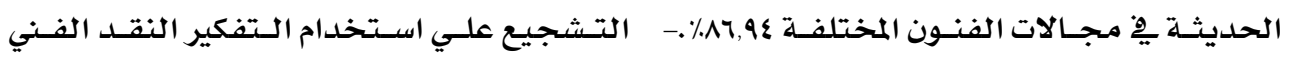

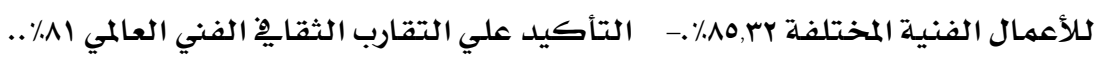

هـ القيم التربوية:

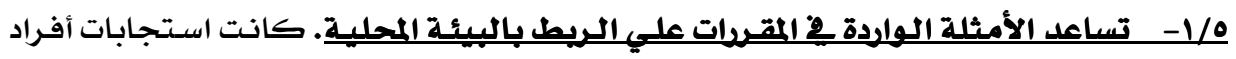

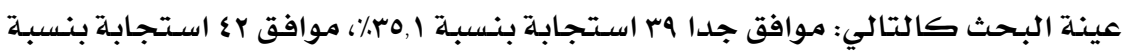

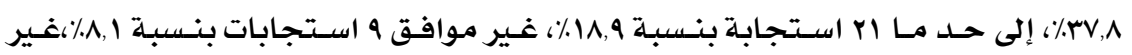

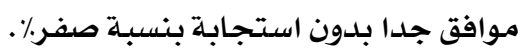

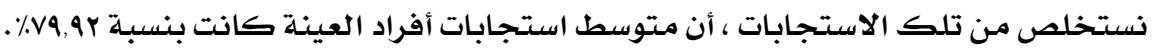

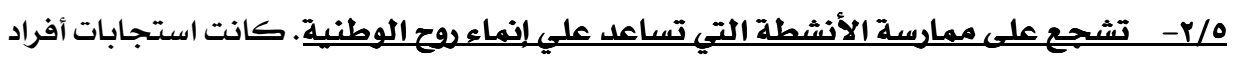

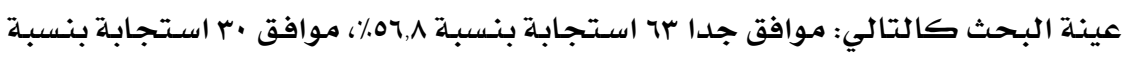

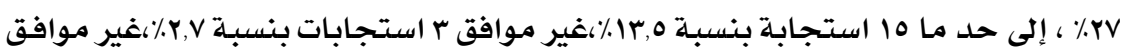




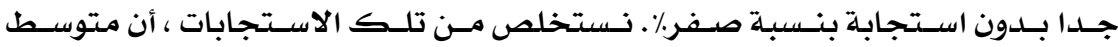

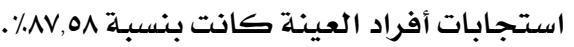

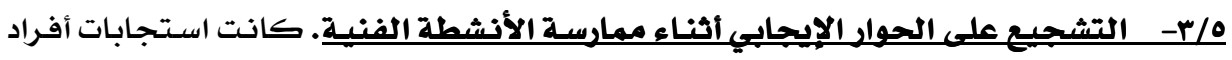

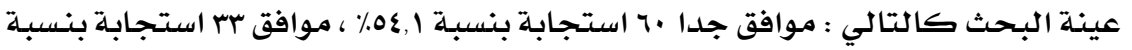

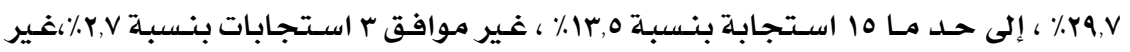

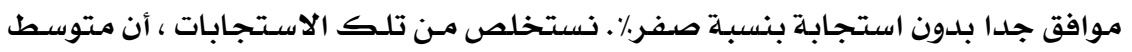

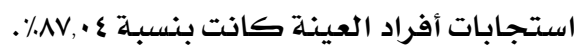

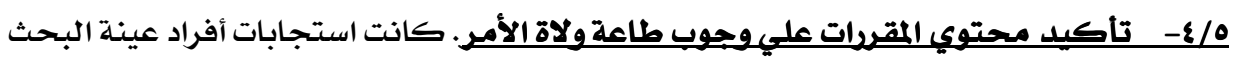

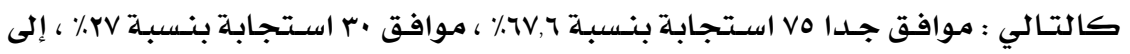

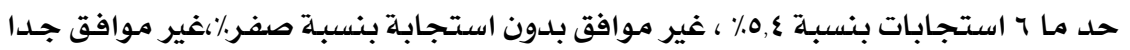
بدون استجابة بنسبة صفر٪

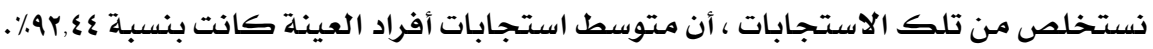

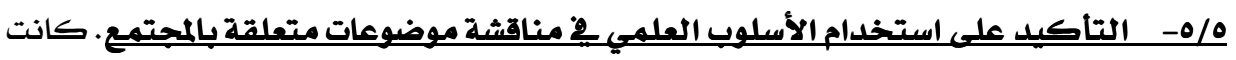

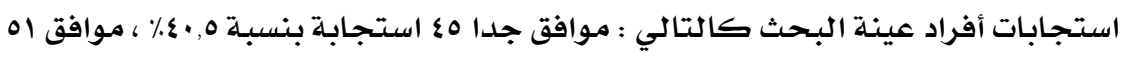

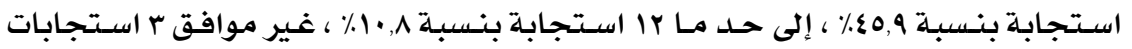

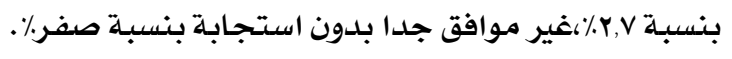

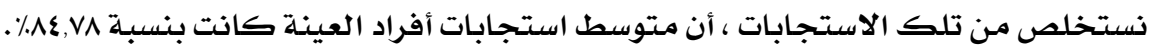

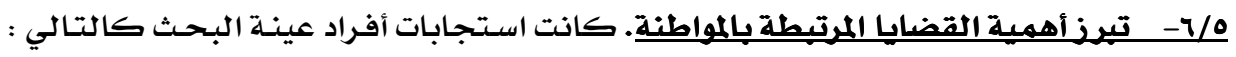

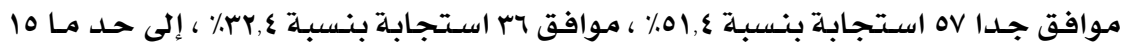

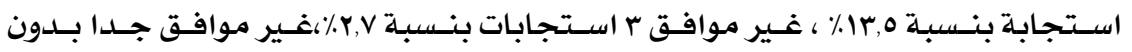

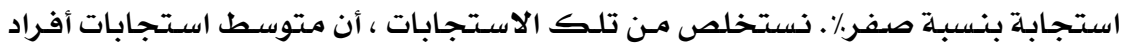

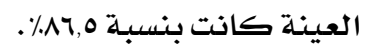
-V/0- تحتوي علي قيم مثل(الدولاء -الانتمـاء- الحقوقوالواجبـات- السلام- الأمـن-

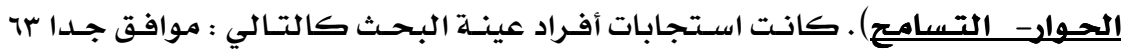

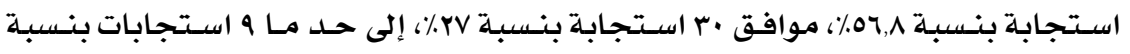

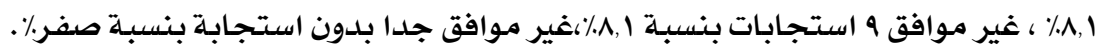

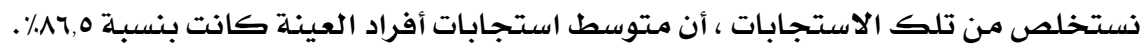

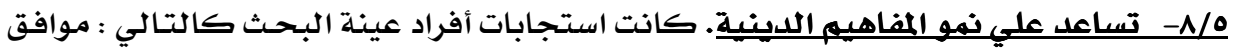

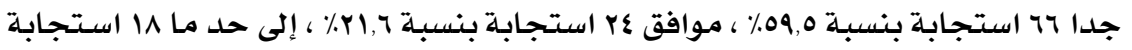

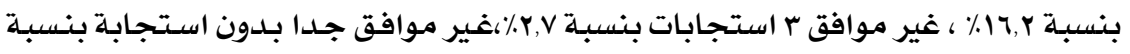




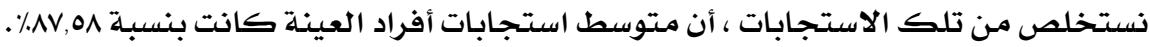

جدول رقم (0) يوضح ترتيب عدد استجابات والنسبة المئوية والمتوسط الحسابي لأفراد العينة.

\begin{tabular}{|c|c|c|c|c|c|c|c|c|c|}
\hline 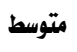 & 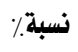 & 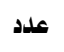 & 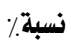 & عدد & 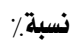 & علد & 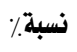 & 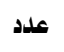 & 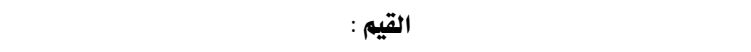 \\
\hline ar, $\{\xi$ & . & - & $0, \xi$ & 1 & rr & $r \cdot$ & $7 v, \eta$ & vo & تأكيد محتوي التقررات علي وجوب طاعة ولاة الأمر. \\
\hline$\Delta \vee, \Delta \Lambda$ & $r, Y$ & $r$ & $i r, 0$ & 10 & rr & r. & 07,1 & $\pi$ & تشجع على ممارسة الأنشطة التي تساعد علي إنماء روح الوطنية. \\
\hline$A \vee, O \Lambda$ & $r, r$ & r & $17, r$ & in & $M, T$ & r६ & $\Delta 9,0$ & 79 & تساعد علي نمو المفاهيه الدينية. \\
\hline$\Delta v, \cdot \varepsilon$ & $r, r$ & $r$ & $i r, 0$ & 10 & $r q, r$ & $r$ & $0 \leqslant, 1$ & ๆ. & التشجيع على الحوار الإيجابي أثناء ممارسة الأنشطة الفنية. \\
\hline$\wedge 1,0$ & $r, r$ & $r$ & $i r, 0$ & 10 & ru, & rq & $01, \varepsilon$ & or & ت تبرز أهمية القضايا المرتبطة بالمواطنة. \\
\hline$\wedge 1,0$ & $\Lambda, 1$ & 9 & $\Lambda, 1$ & 9 & rv & r. & $\Delta 7,1$ & it & تحتوي علي قيم مثل(الولاء -الاتتهاء_الحقوق والواججبات_السلام_الأمن_الحوار_التسامح). \\
\hline$\Lambda \varepsilon, \vee \wedge$ & $r, r$ & r & $1 \cdot, 1$ & ir & $\$ 0,9$ & 01 & $\varepsilon \cdot, 0$ & \&o & التأكيد على أستخدم الأسلوب العلمي في مناقشة موضوعات متعلقة بالمجتمع.. \\
\hline va,qr & $\Lambda, 1$ & 9 & 14,9 & r & $r v, \Lambda$ & $\varepsilon r$ & ro, 1 & rq & تساعد الأمثلة الواردة في المقررات علي الربط بالبيئة المحلية. \\
\hline
\end{tabular}

من خلال النتائج السابقة والموضحة يِّ الجدول رقم (ه ) يمكن ترتيب قيم المواطنـة التربويـة

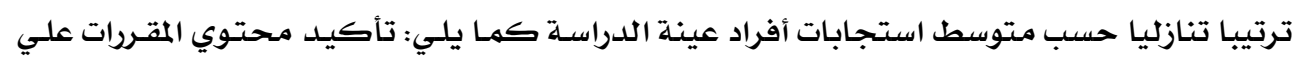

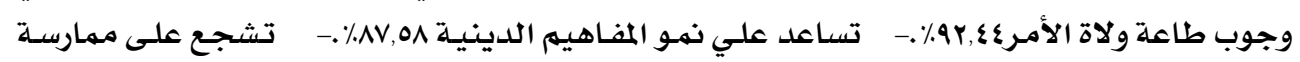

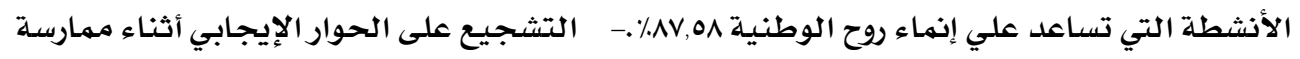

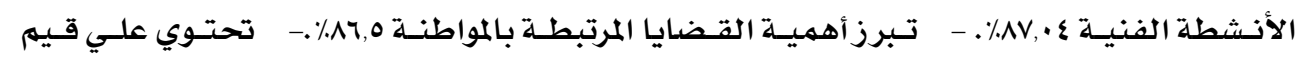

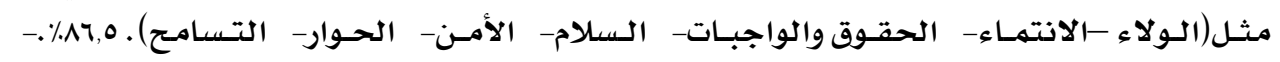

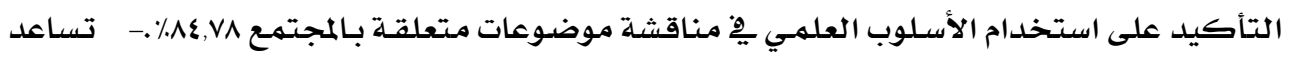

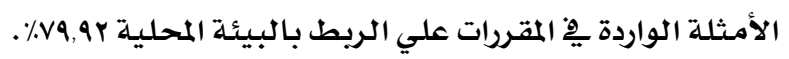

\section{تفسير النتائج:}

من خلال النتائج السابقة وجدنا التالي :

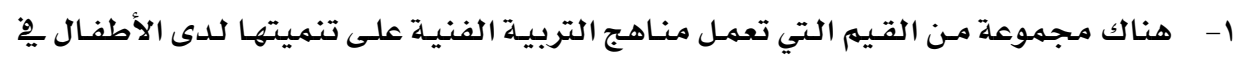

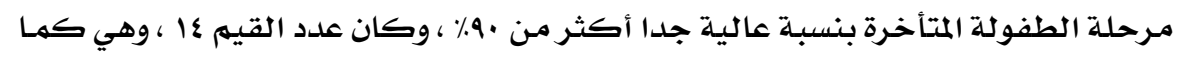

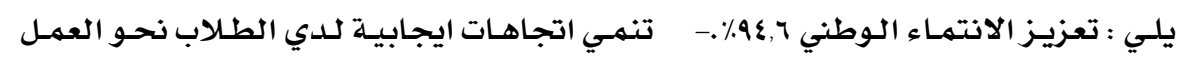

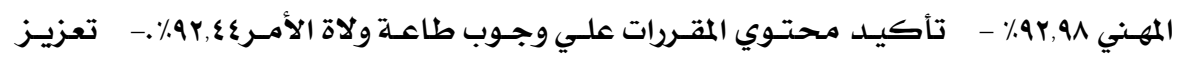

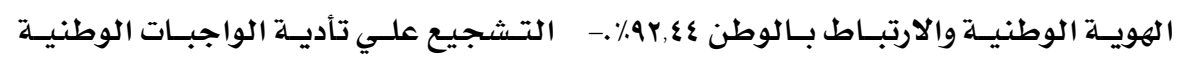

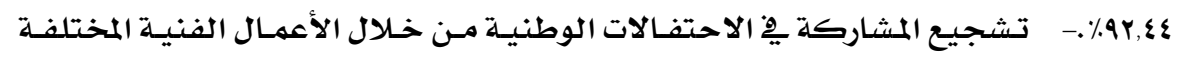

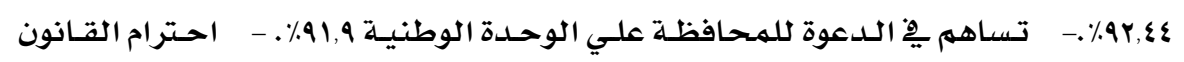

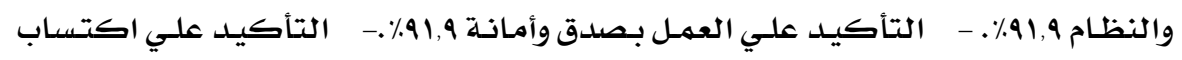

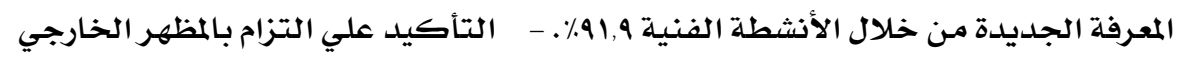

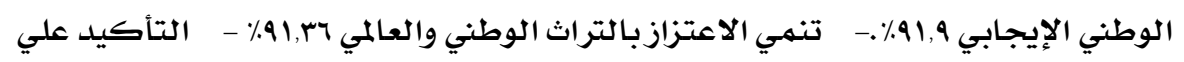




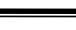
مجلة بحوث التربية النوعية - علد ال

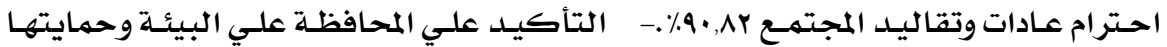
$\therefore q \cdot, r \wedge$

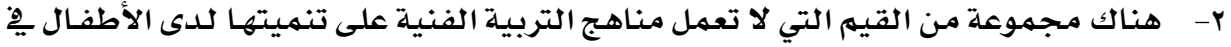
مرحلة الطفولة المتتأخرة ، حيث وجد أن نسبة تنهيتها له تتجاوز ·^ـ٪ ، وكان عدد القيهم ب ،

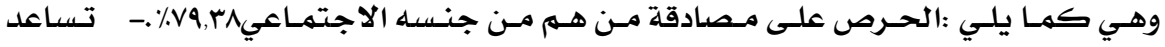

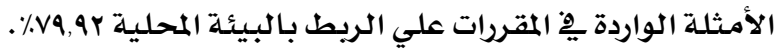

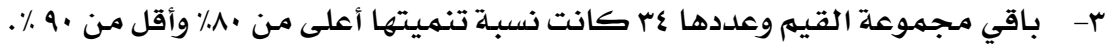

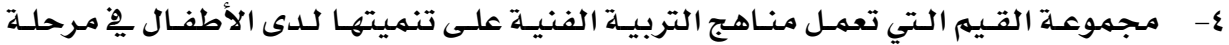

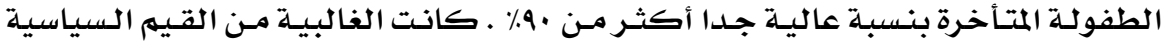

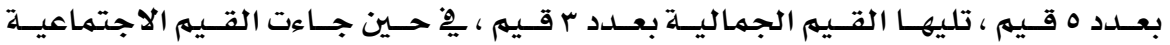
والاقتصادية بنفس العدد ب قيهم ـ أما القيم التربوية فكانت ا قيهم .

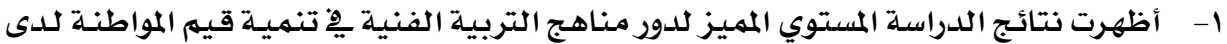

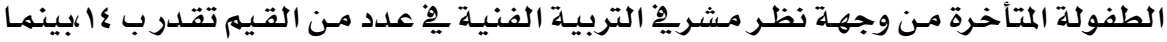
هنالك العديد من القيهم تتطلب المزيد من الجهد ، ولذلك يوصي البـاحثون بضرورة التأكيد

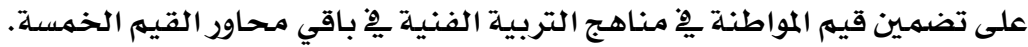

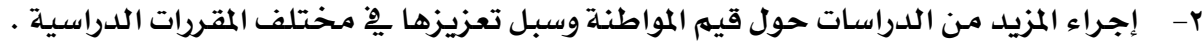
ب- إحداث التكامل لتدريس قيهم المواطنـة بين المقررات الدراسية ِِِ المراحل الدراسية المختلفة . 


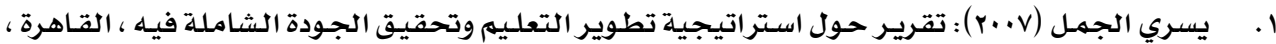
وزارة التربية والتعليه.

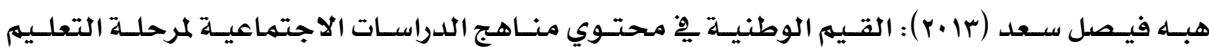

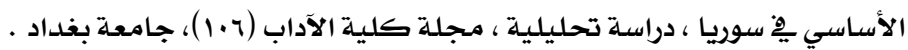

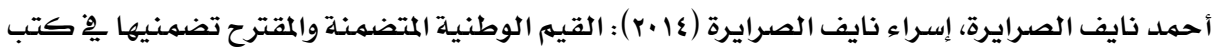
التربية الاجتماعية والوطنية للمـرحلة الأسـاسية الدنيا يِّ الأردن ، مجلـة كليـة التربيـة ، جامعـة الأزهـر

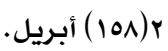

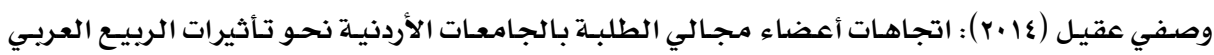

على تنمية قيم المواطنة : دراسلة ميدانية، مجلة اتحاد الجامعات العربية للآداب ال|(r) .

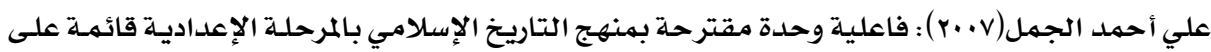

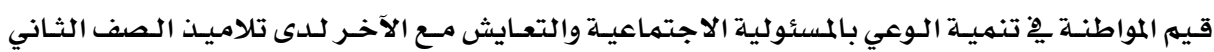
الإعدادي، مجللة الجمعية التربوية للدراسـات الاجتماعية بكلية التربية، جامعـة عين شمس (r) (r) خالد قرواني (rا ·ץ ): الاتجاهات المعاصـرة للتربيـة على المواطنـة، جامعـة القـدس المفتوحسة، مقال منشور hpl/www.qou.edu/Arabic/researchprogram/ researchers pages. على الانترنت

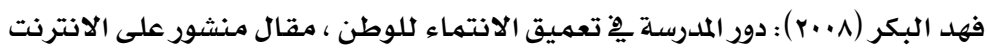
hppt/www.plamoon.net/7/topic-15-567.html.

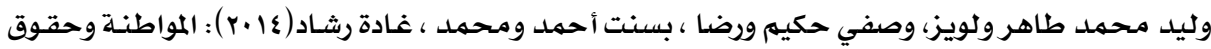
الإنسان ،وزراه التربية والتعليه ، قطاع الكتب، القاهرة.

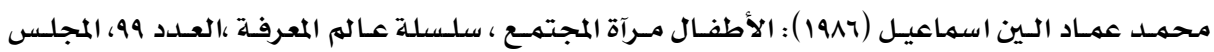
الوطني للثقافة والفنون والآدب، الكويت.

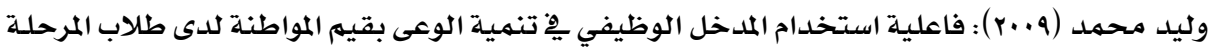

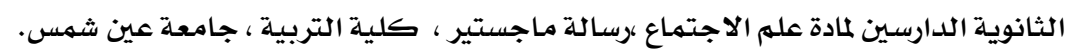

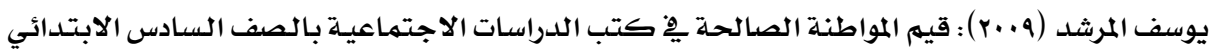
بالمملكة العربية السعودية ،مجلة كلية التربية ببور سعيد ، (7)،جامعة قناة السويس، مصر.

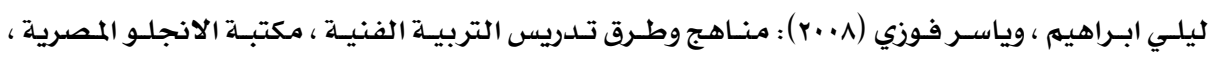
القاهرة.

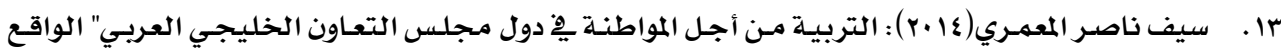

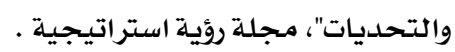

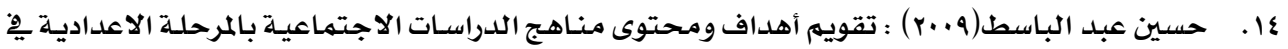
ضوء قيه المواطنة، مجلة الجمعية التربوية للدراسات الاجتهاعية بكلية التربية ،جامعة عين شمس.

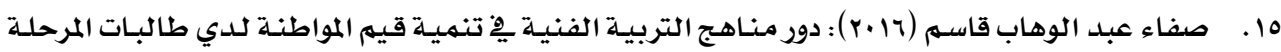
المتوسطة ، مجلة جامعة طيبة، بحوث عربية ٌِِ مجالات التربية النوعية، السعودية. 


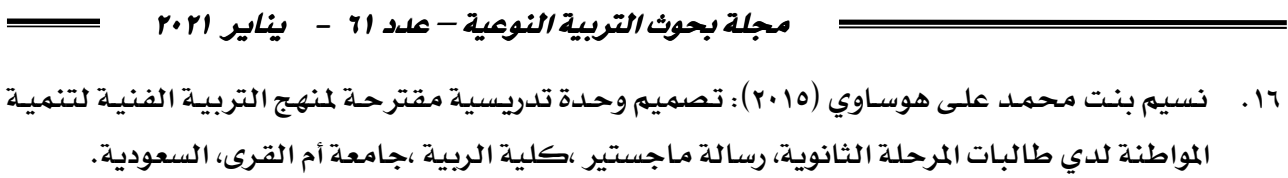

1.Harland, J. (2002) A curriculum model for citizenship education, In:D. Lawton, et al., (eds), Education for citizenship, London: MP Continuum.

2.Bugliarello,G (2002)The interdisciplinary imperative: Interactive research and education still an elusive goal in academic, Technology and Society. Polytechnic University of New York.

3.Daignault ,L.(2003). Children's Creative Musical Thinking Within the Context of a Computer -Supported Improvisational Approach to Composition. Doctoral Dissertation, Northwestern University, Boston, Massachusetts, USA.

4.Ross,A. (2002) Citizenship education and curriculum theory In: Citizenship education and the curriculum. Edited by David Scott and Helen Lawson. Ablex Publishing Westport, CT.

5.Smith,A. (2003) Citizenship education in Northern Ireland : Beyond national identity ? Journal of education, 33 (1).

6.Patrick, J. (2003) Teaching democracy globally, internationally , and comparatively : the 21 st- Century civic mission of school, paper presented at the 3rd annual R. freeman Butts institute on civic learning of Teacher Education , Indianapolis, Indiana and to the Cavities Latin America Leaders Seminar in Santo Domingo, Republishing Dominican.

7.Georon,L. (2003) learning to teach citizenship in the secondary education. London; Roueledage . Falmer.

8.Cogan,J.\& Derricott, R.(2000) Citizenship for the 21 st Century : An International Perspective on Education Kogan Page . London, United Kingdom.

9.Brynigolson , R. (2010) Teaching Art. A complete Guide for the Classroom, Portage and Main Press, Canada. 


\section{هلمق رقم (1) \\ (نموذة استبانة)}

السلام عليكم ورحمـة الله وبركاته :

يقوم الباحثون بإجراء دراسـة بعنوان:

\section{دور مناهج التربية الفنية يِّ تنمية قيم المواطنة لدي مراحل الطفولة المتأخرة.}

، وذلك للتعـرف على دور منـاهـج التربيـة الفنيـة منـاهج فِّ مـدراس التعلـيم العـام بالمملكـة

العربية السعوديية.

مـع خالص شكرنا وتقديرنا لكم

الباحثون

الاسهم ( اختياري) :

المؤهل العلمي : الماري

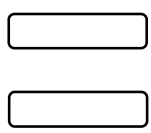

بكالوريوس تخصص تربية فنية أو فنون

بكالوريوس غير تخصصات تربية فنية أو فنون.

سنوات الخدمة :

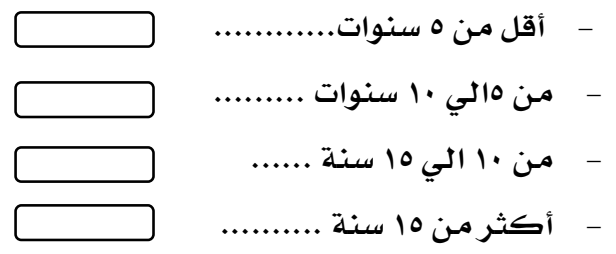




\section{مجلة بحوث التريية النوعية - علد}

الرجاء قراءة كل فقرة والاجابة بالنسبـة المناسبـة.

\begin{tabular}{|c|c|c|c|c|c|c|}
\hline غير موافق جدا & | غير موافق & 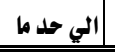 & 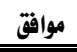 & | موافق جدا & 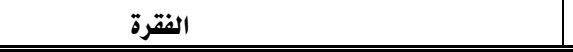 & $\therefore$ \\
\hline & & & & & \multicolumn{2}{|c|}{ قيم المواطنة السياسية: } \\
\hline & & & & & |تعزيز الاتتماء الوطني . & .1 \\
\hline & & & & & | تساهم في الدعوة للمحافظة علي الوحدة الوطنية. &.$r$ \\
\hline & & & & & | تشجع علي النقد الإيجابي البناء. r/10/19 &.$\mu$ \\
\hline & & & & & | تعزيز الهوية الوطنية والارتباط بالوطن. &.$\varepsilon$ \\
\hline & & & & & | التشجيع علي تأدية الواجبات الوطنية . & .0 \\
\hline & & & & & | احترام القانون والنظام . & .7 \\
\hline & & & & & |تهتم بوضع معايير الحقوق الفنية للأعمال المختلفة. &.$V$ \\
\hline & & & & & | تهتم بضرورة السلام العالمي بين الشعوب. &.$\wedge$ \\
\hline & & & & & |تنمي مبلأ المساواة في الحقوق والواجبات. & .9 \\
\hline & & & & & \multicolumn{2}{|c|}{ قيم المواطنة الاجتهماعية: } \\
\hline & & & & & | التأكيد علي احترام عادات وتقاليد المجتمع. & .1. \\
\hline & & & & & |تنمي اتجاهات ايجابية لدي الطلاب نعو العمل المهني. & .11 \\
\hline & & & & & | التأكيد علي ضرورة التسامح مع الاخر. & $.1 r$ \\
\hline & & & & & |تعزيز مبدأ احترام طبائع البشر (الاعراق - الشعوبـالثقافات). & $.1 \%$ \\
\hline & & & & & | تعزيز تقدير ثقافة الشعوب الأخرى. & $.1 \varepsilon$ \\
\hline & & & & & | تنني الاعتزاز بالتراث الوطني والعالمي. & .10 \\
\hline & & & & & | التكاكيد علي احترام الرأي الاخر. & .17 \\
\hline & & & & & | اكتشاف الأسرار التتعلقة بالبيئة. & $.1 \mathrm{~V}$ \\
\hline & & & & & | الاهتمام بتفسير العلاقات والتي تتميز بكونها الارقي فكريا . & .11 \\
\hline & & & & & | الحرص على مصادقة من هم من جنسه الاجتماعي. & .19 \\
\hline & & & & & | العمل على قضاء وقت أكبر في العمل الجماعي. & $r$. \\
\hline & & & & & |تشجع علي حل الخلافات بطرق سلمية. & .41 \\
\hline & & & & & | التأكيل علي حل المشكلات بالعوار الهادف بين الطلاب &.$M Y$ \\
\hline & & & & & | تساهم في التعرف علي ثقافة المجتعات المختلفة. &.$r r$ \\
\hline & & & & & [تشجع في المساهمة في الاعمال الخيرية من خلال المنتجات الفنية. & $. r \leqslant$ \\
\hline & & & & & |تهتم بزيارة المواقع التاريخية والأثرية في الوطن. &.$r 0$ \\
\hline & & & & & \multicolumn{2}{|c|}{ قينيم المواطنة الاقتصادية: } \\
\hline & & & & & | التأكيد علي العمل بصدق وأمانة. & .47 \\
\hline
\end{tabular}




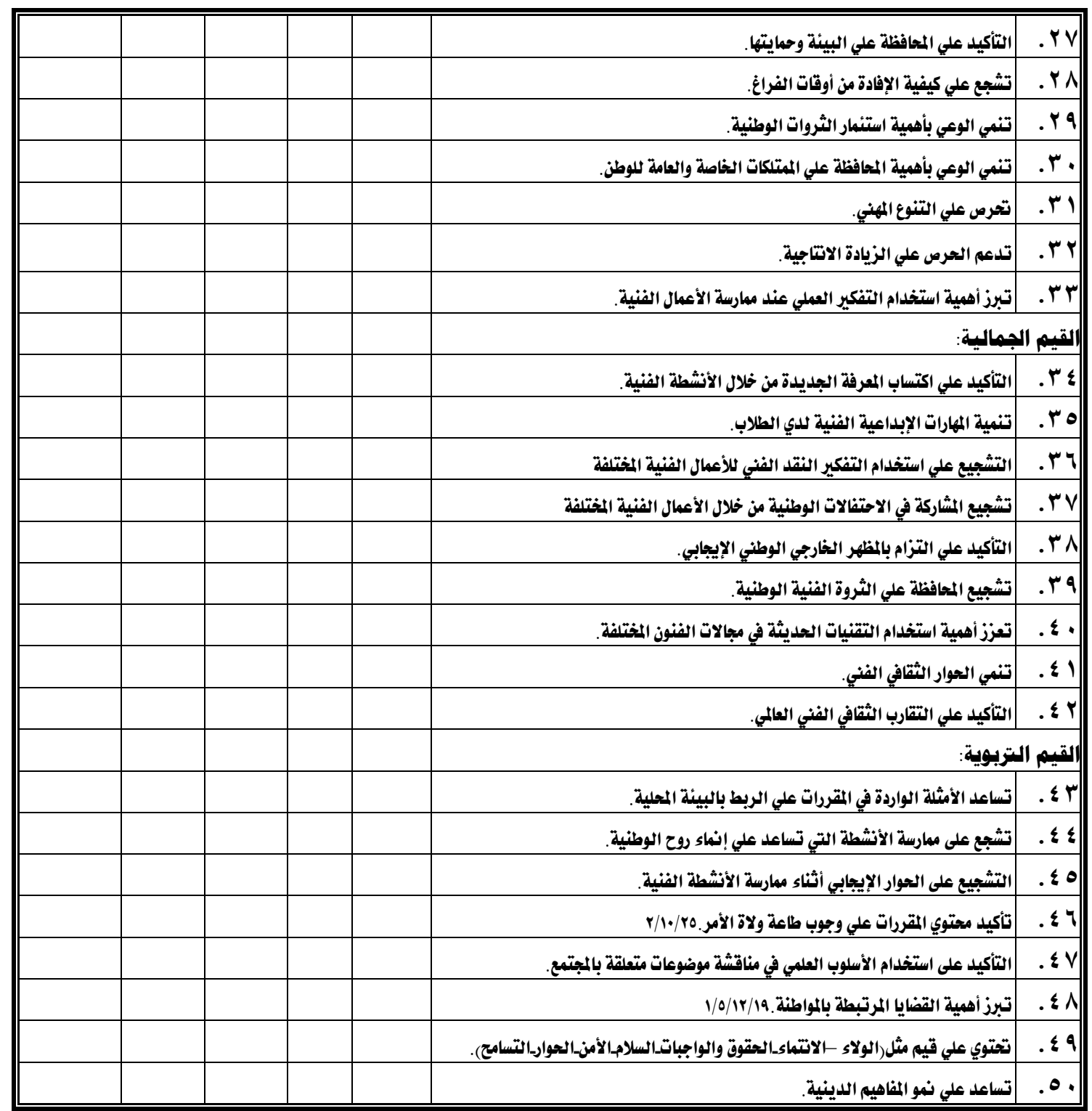




\section{The role of art education curricula in developing citizenship values in late childhood stages.}

\section{Abstract}

Childhood study is an important part of caring for both the present and the future, as children form a large segment of society. It is one of the studies that inferred the crystallization of the scientific and intellectual awareness of society, which leads to the formation of flexible, objective, integrated and comprehensive ideas about the person, his present and his future.

In view of the rapid change and development that included all aspects of social, social and cultural life, the world today is facing great and enormous challenges, which had an impact on the relations between members of the same community, and here comes the role of citizenship in establishing a set of human relationships based on belonging, loyalty and respect for laws, regardless of the difference. On the intellectual grounds or philosophical references for this society.

The voices calling for the necessity of teaching and learning of citizenship through school curricula have been raised, which is one of the goals that the education system in the Kingdom of Saudi Arabia seeks to develop among children.

The aim of the research is to identify the values of citizenship that art education curricula seek to develop in late childhood from the point of view of teachers and supervisors, and the researchers used the descriptive and analytical approach by applying a questionnaire consisting of several axes (political values, social values, economic values, aesthetic values, Educational values) Contains fifty sample phrases from art education teachers and supervisors. The results of the research revealed the role of art education curricula in developing citizenship values from the viewpoint of art education teachers and supervisors in late childhood.

The researchers have reached a set of conclusions and recommendations, which can be used by officials, experts and curriculum specialists in gaining familiarity with the concepts of citizenship and enhancing them through art education curricula. 